\title{
Baetidae (Insecta, Ephemeroptera) ocorrentes em Roraima, Brasil: novos registros e chaves para gêneros e espécies no estágio ninfal
}

\author{
Jesine Netto Falcãoํㅏㄹ Frederico Falcão Salles ${ }^{2} \&$ Neusa Hamada ${ }^{1}$
}

'Coordenação de Biodiversidade, Divisão de Curso de Entomologia, Instituto Nacional de Pesquisas da Amazônia, Avenida André Araújo 2936,
69067-375 Manaus-AM, Brasil. jesine@gmail.com; nhamada@inpa.gov.br
${ }^{2}$ Departamento de Ciências Agrárias e Biológicas, Universidade Federal do Espírito Santo, 29933-415 São Mateus-ES, Brasil. ffsalles@gmail.com

\begin{abstract}
Baetidae (Insecta, Ephemeroptera) from Roraima, Brazil: new records and a key to genera and species at nymphal stage. Roraima is one of the Brazilian states where least is known regarding the family Baetidae; to date only four species have been recorded from the state. The aim of the present study is to improve knowledge of the family in Roraima based on collections that are mainly from northeastern and southeastern portions of the state. Thirty-two species were found; of this total, 14 are new records for the entire Northern Region of Brazil, and four species are new for the country (Camelobaetidius ortizi Dominique \& Thomas, 2002, Cloeodes barituensis Nieto \& Richard, 2008, Paracloeodes pacawara Nieto \& Salles, 2006 and Waltzoyphius roberti Thomas \& Peru, 2002). Except for Moribaetis Waltz \& McCafferty, 1985, Tomedontus Lugo-Ortiz \& McCafferty, 1995, Tupiara Salles, Lugo-Ortiz, Da-Silva \& Francischetti, 2003 and Varipes Lugo-Ortiz \& McCafferty, 1998, all of the remaining genera that had been recorded from Brazil were found. One genus and one Cryptonympha species were found to be new to science.
\end{abstract}

KEYWORDS. Amazonia; aquatic insects; identification key; new species record; taxonomy.

RESUMO. Baetidae (Insecta, Ephemeroptera) ocorrentes em Roraima, Brasil: novos registros e chaves para gêneros e espécies no estágio ninfal. Roraima é um dos estados de menor conhecimento acerca da família Baetidae no Brasil, com apenas quatro espécies formalmente registradas. Através de coletas realizadas principalmente nas regiões nordeste e sudeste de Roraima, o presente trabalho tem por objetivo ampliar o conhecimento a respeito da família no estado. Foram encontradas 32 espécies, sendo dessas, 14 novas ocorrências para a Região Norte e quatro novos registros para o Brasil (Camelobaetidius ortizi Dominique \& Thomas, 2002, Cloeodes barituensis Nieto \& Richard, 2008, Paracloeodes pacawara Nieto \& Salles, 2006 e Waltzoyphius roberti Thomas \& Peru, 2002). Exceto pelos gêneros Moribaetis Waltz \& McCafferty, 1985, Tomedontus Lugo- Ortiz \& McCafferty, 1995, Tupiara Salles Lugo-Ortiz, Da-Silva \& Francischetti, 2003 e Varipes Lugo-Ortiz \& McCafferty, 1998, todos os gêneros registrados para o Brasil foram encontrados. Um gênero e uma espécie de Cryptonympha encontrados são novos para a Ciência.

PALAVRAS-CHAVE. Amazônia; chave de identificação; insetos aquáticos; novos registros de espécies; taxonomia.

O conhecimento a respeito da ordem Ephemeroptera no Brasil tem recebido diversas contribuições nos últimos anos (e.g. Salles et al. 2004b; Dias et al. 2005; Salles \& Serrão 2005; Nieto \& Salles 2006; Salles \& Molineri 2006; Salles 2007; Domínguez et al. 2009; Falcão et al. 2010; Gonçalves et al. 2010a, 2010b; Lima et al. 2010; Mariano 2010; Salles et al. 2010b, 2011b). No entanto, perante a grande extensão do território brasileiro, tais avanços ainda se mostram insuficientes para representar adequadamente a nossa fauna. Muitos estados, e até mesmo regiões, permanecem pouco estudados, restando muitas lacunas no conhecimento e distribuição da ordem (Salles et al. 2004b). Além disso, grande parte da informação existente é oriunda de descrições taxonômicas, havendo pouca informação sobre a distribuição das espécies.

Baetidae é uma das famílias mais abundantes e diversas da ordem Ephemeroptera, e, é uma das mais estudadas e melhor documentadas do país. Devido aos grandes esforços realizados, a família teve o número de espécies praticamente dobrado nos últimos 10 anos, contando atualmente com 71 espécies em 21 gêneros (Salles et al. 2011a). Apesar desse grande avanço, estima-se que esses números são baixos, quando considerada a falta de informações para grande parte do território nacional.

Embora a Região Norte apresente um dos maiores números de espécies de Baetidae do país, com 24 registros, tal documentação se limita principalmente a pequenas áreas dos estados do Amazonas e Pará (Salles et al. 2004b; Salles \& Serrão, 2005; Nieto \& Salles 2006; Salles 2007; Salles et al. 2010b; 2011b; Cruz et al. 2011). Informações referentes aos outros estados da região permanecem praticamente inexistentes. O estado de Roraima ocupa cerca de 2,6\% do território brasileiro (ITERAIMA 2005), no qual está inserido o maior bloco contínuo de savanas da Amazônia brasileira (Barbosa et al. 2005). Atualmente, quatro espécies estão formalmente registradas para o estado: Aturbina nigra Salles, Boldrini \& Shimano, 2011, Camelobaetidius matilei Thomas \& Peru, 2003, Chane baure Nieto, 2003 e Harpagobaetis gulosus Mol, 1986 (Salles \& Serrão 2005; Salles 2007; Falcão et al. 2010; Salles et al. 2011b). 
O presente trabalho tem como objetivo ampliar a documentação da família Baetidae no estado de Roraima, contribuindo com novos registros de táxons para o estado, para a Região Norte e para o Brasil, além de apresentar uma chave para identificação dos gêneros e espécies encontrados.

\section{MATERIAL E MÉTODOS}

Neste trabalho foi analisado material de 66 cursos d'água. Parte desse material estava previamente depositado na coleção de Invertebrados do INPA. O restante foi adquirido através de coletas realizadas em diversos cursos d'água pertencentes à Bacia do Rio Branco. Devido à dificuldade de acesso a algumas áreas e aos conflitos de terras que ocorrem na região, as amostragens se concentraram a nordeste e a sudeste do estado. O material examinado é apresentado com um código para cada ponto amostrado, número de indivíduos adquiridos entre parênteses e a data de coleta. As informações sobre a localidade e coordenadas de cada ponto, assim como coletores, encontram-se na Tabela I. O material listado no presente estudo encontra-se depositado na Coleção de Invertebrados do Instituto Nacional de Pesquisas da Amazônia, Manaus, Brasil.

A identificação do material foi realizada a partir das chaves presentes em Domínguez et al. (2006) e Salles (2006), além de consulta a uma série de artigos que tratam da taxonomia de Baetidae na América do Sul (veja lista de referências). Grande parte desses artigos encontra-se disponíveis em formato pdf a partir do site Ephemeroptera Galactica (http://www.famu.org/mayfly/).

Para a elaboração da chave taxonômica foram utilizados exemplares de cada espécie coletada no estado de Roraima, assim como bibliografia referente a elas (veja lista de referências). Quando necessário, lâminas permanentes, utilizando Euparal ${ }^{\circledR}$ como meio de inclusão, foram montadas para se observar e fotografar estruturas selecionadas. A fim de facilitar a utilização da chave foram montadas pranchas para cada espécie com imagens das suas principais características diagnósticas. As imagens foram feitas utilizando uma máquina fotográfica digital Olympus, Q-color 5 acoplada a um miscrocópio óptico Zeiss com aumento máximo de $1.000 x$ e uma máquina fotográfica digital Nikon, modelo Coolpix 4300 acoplada a um microscópio estereocópico Zeiss de aumento máximo de 50x. A única exceção refere-se à prancha de Adebrotus amazonicus Lugo-Ortiz \& McCafferty, 1995 (Figs. 1-5), elaborada a partir de ilustrações modificadas de Salles (2010).

A chave não distingue as espécies de Callibaetis Eaton, 1881, que foram apenas morfotipadas, devido a impossibilidade de identificar as ninfas até espécie sem uma associação prévia com os adultos. A chave proposta foi baseada nas chaves de Salles \& Serrão (2005), Domínguez et al. (2006), Nieto \& Salles (2006) e Salles (2006).

Tabela I. Número do ponto de coleta, município no estado de Roraima, Brasil, localidade do ponto de coleta (coordenadas em graus decimais) e coletores dos exemplares de Baetidae (Ephemeroptera) no campo. Coletores: JNF = Jesine Netto Falcão; CASA = Carlos Augusto Silva Azevêdo; LMF = Livia Maria Fusari; FFS = Frederico Falcão Salles; NH = Neusa Hamada, JOS = Jeferson Oliveira da Silva, AMOP = Ana Maria Oliveira Pes, SRMC = Sheyla R.M. Couceiro, RLFK = Ruth L. Ferreira-Keppler, JLN = Jorge L. Nessimian.

\begin{tabular}{|c|c|c|c|}
\hline Ponto (PT) & Município & Localidade & Coletores \\
\hline 1 & Alto Alegre & Igarapé do $\mathrm{Au} \mathrm{Au}(2,93872 ;-61,0515)$ & JNF, LMF, CASA \\
\hline 2 & Alto Alegre & Igarapé do Funil, prox. a entrada do ramal São Silvestre $(2,912 ;-61,0089$ & JNF, LMF, CASA \\
\hline 3 & Alto Alegre & Igarapé da $1^{\mathrm{a}}$ ponte do ramal do Traiano $(3,013 ;-61,1603)$ & JNF, LMF, CASA \\
\hline 4 & Alto Alegre & Igarapé Caiçara. Sítio Manancial. Km 35. RR-205 (2,91114; -60,988) & JNF, LMF, CASA \\
\hline 5 & Bonfím & Rio Arraia $(3,35044 ;-59,904)$ & NH \\
\hline 6 & Bonfím & Igarapé Jacaretinga $(3,31842 ;-59,9381)$ & JNF, LMF, CASA \\
\hline 7 & Boa Vista & Igarapé do Mansur. Cidade Satélite $(2,87219 ;-60,7813)$ & JNF, LMF, CASA \\
\hline 8 & Bonfím & Igarapé da Capivara. Ramal do Cantá $(2,74589 ;-60,4724)$ & JNF, LMF, CASA \\
\hline 9 & Boa Vista & Igarapé das Cobras. Cidade Satélite $(2,86525 ;-60,7733)$ & JNF, LMF, CASA \\
\hline 10 & Cantá & Igarapé Memeca. RR-170. Ramal da Serra Grande $(2,53203 ;-60,8001)$ & JNF, LMF, CASA \\
\hline 11 & Cantá & Igarapé do Pedral. Faz. Paraíso. $3^{\mathrm{a}}$ ponte. RR-170 $(2,55589 ;-60,805)$ & JNF, LMF, CASA \\
\hline 12 & Cantá & Igarapé da ponte da Fazenda do Sr. Pedro Rodrigues $(2,55769 ;-60,7479)$ & JNF, LMF, CASA \\
\hline 13 & Cantá & Igarapé da III ponte. Km 17,5. RR-170 (2,67733; -60,7009) & JNF, LMF, CASA \\
\hline 14 & Cantá & Igarapé da I ponte. Km 7. RR-170 (2,74597; -60,6685) & JNF, LMF, CASA \\
\hline 15 & Boa Vista & Rio Murupú $(3,02119 ;-60,7758)$ & JNF, LMF, CASA \\
\hline 16 & Boa Vista & Igarapé Água Boa de Cima. Região de Bom Intento $(2,95458 ;-60,5779)$ & JNF, LMF, CASA \\
\hline 17 & Amajari & Igarapé Cocal. RR-203. Serra de Tepequém $(3,73589 ;-61,7258)$ & JNF, LMF, CASA \\
\hline 18 & Boa Vista & Igarapé Água Boa de Baixo $(2,77519 ;-60,9399)$ & JNF, LMF, CASA \\
\hline 19 & Boa Vista & Igarapé Urubuzinho. Sítio do Sr. Feitosa $(2,78719 ;-60,8887)$ & JNF, LMF, CASA \\
\hline 20 & Boa Vista & Igarapé Paquinha. Afluente do Paca $(2,74794 ;-60,8243)$ & JNF, LMF, CASA \\
\hline
\end{tabular}


Tabela I. Continuação.

\begin{tabular}{|c|c|c|c|}
\hline Ponto (PT) & Município & Localidade & Coletores \\
\hline 21 & Boa Vista & Igarapé Bacabal. Faz. Bacabal. Sr. Fábio Socum $(2,68506 ;-60,9876)$ & JNF, LMF, CASA \\
\hline 22 & Boa Vista & Igarapé do Km 580. BR-174 (3,42486; -60,8978) & JNF, LMF, CASA \\
\hline 23 & Boa Vista & Igarapé do Km 582. BR-174 (3,44469; -60,9067) & JNF, LMF, CASA \\
\hline 24 & Boa Vista & Igarapé da esquerda, afluente do Rio Murupú. BR-174. $(3,021 ;-60,7773)$ & JNF, LMF, CASA \\
\hline 25 & Amajari & Igarapé da Fazenda Areia Branca. Serra de Tepequém $(3,72264 ;-61,7178)$ & JNF, LMF, CASA \\
\hline 26 & Amajari & Igarapé da Fazenda Pau Barú. Serra de Tepequém $(3,69033 ;-61,7009)$ & JNF, LMF, CASA \\
\hline 27 & Amajari & Igarapé do Pedral. Serra de Tepequém $(3,62064 ;-61,6376)$ & JNF, LMF, CASA \\
\hline 28 & Boa Vista & Igarapé Tipiquirí. Baixo Uraricoera. Faz. Caracaizinho $(3,47833 ;-60,7886)$ & JNF, LMF, CASA \\
\hline 29 & Boa Vista & Igarapé Lontra. Faz. Caracaraizinho. BR-174 (3,46872; -60,7875) & JNF, LMF, CASA \\
\hline 30 & Boa Vista & Rio Cauamé $(2,86833 ;-60,7401)$ & $\begin{array}{c}\text { NH, RLFK, SRMC, JNF, } \\
\text { LMF, CASA }\end{array}$ \\
\hline 31 & Pacaraima & Igarapé Sgt. Ávila $(4,44535 ;-61,1243)$ & NH, JOS, FFS, MP, LFS \\
\hline 32 & Pacaraima & Igarapé Bananal $(4,43275 ;-61,2183)$ & NH, JOS, RLFK, SRMC \\
\hline 33 & Pacaraima & Igarapé afluente do Bananal $(4,43275 ;-61,2183)$ & NH, JOS, FFS, MP, LFS \\
\hline 34 & Pacaraima & Cachoeira do Igarapé Bananal $(4,42967 ;-61,2127)$ & $\mathrm{NH}$ \\
\hline 35 & Amajari & Rio Ereu $(4,03347 ;-61,3866)$ & $\begin{array}{l}\text { NH, JOS, FFS, MP, LFS, } \\
\text { JNF, LMF, CASA }\end{array}$ \\
\hline 36 & Boa Vista & Igarapé Truaru $(3,28208 ;-60,8499)$ & NH, JOS, FFS, MP, LFS \\
\hline 37 & Uiramutã & Rio Contigo $(4,38769 ;-60,3906)$ & $\begin{array}{c}\text { NH, AMOP, CASA, RLFK, } \\
\text { JLN }\end{array}$ \\
\hline 38 & Uiramutã & Rio Contigo $2(4,33953 ;-60,4868)$ & $\begin{array}{c}\text { NH, AMOP, CASA, RLFK, } \\
\text { JLN }\end{array}$ \\
\hline 39 & Pacaraima & Igarapé da ponte de Madeira, acesso à vila Surumu (4,21894; -60,8883) & NH, JOS, FFS, MP, LFS \\
\hline 40 & Pacaraima & Rio Surumu $(4,58494 ;-60,9236)$ & $\begin{array}{c}\text { NH, AMOP, CASA, RLFK, } \\
\text { JLN }\end{array}$ \\
\hline 41 & Pacaraima & Igarapé do Sorocaima $(4,42198 ;-61,1643)$ & $\mathrm{NH}$ \\
\hline 42 & Caracaraí & Rio Branco, cachoeira do Bem Querer $(1,92858 ;-61,0026)$ & $\begin{array}{l}\text { NH, JOS, FFS, MP, LFS, } \\
\text { JNF, LMF, CASA }\end{array}$ \\
\hline 43 & São João da Baliza & Igarapé das Lages. Fazenda do Sr. Eufrazio Machado. Vicinal-27 $(1,01658 ;-59,9266)$ & JNF, LMF, CASA \\
\hline 44 & São João da Baliza & Igarapé da Fazenda Cotagipe. Km 9. Vicinal-27 (1,03372; -59,9251) & JNF, LMF, CASA \\
\hline 45 & São João da Baliza & Igarapé Mata Fome. Vicinal-31 $(1,05614 ;-59,8703)$ & JNF, LMF, CASA \\
\hline 46 & Caroebe & Igarapé da ponte do Sítio do Sr. Manoel. Vicinal-04 $(0,742056 ;-59,4078)$ & JNF, LMF, CASA \\
\hline 47 & São João da Baliza & Igarapé da ponte do Ramal Serra Dourada. Vicinal-21 $(1,20731 ;-60,0378)$ & JNF, LMF, CASA \\
\hline 48 & São Luiz & Igarapé da $3^{\text {a }}$ ponte. Km 11. Vicinal-12. Vila Moderna $(1,04569 ;-60,2565)$ & JNF, LMF, CASA \\
\hline 49 & São Luiz & Igarapé da $2^{a}$ ponte. Km 9. Vicinal-12. Vila Moderna $(1,05592 ;-60,2377)$ & JNF, LMF, CASA \\
\hline 50 & São João da Baliza & Igarapé do sitio Boa Esperança. Vicinal-26 $(0,741778 ;-60,1506)$ & JNF, LMF, CASA \\
\hline 51 & São João da Baliza & Igarapé da ponte da Vicinal-26. Km $23(0,7955 ;-60,0828)$ & JNF, LMF, CASA \\
\hline 52 & São João da Baliza & Igarapé do Sítio São Francisco. Km 5. Vicinal-26 (0,906; -59,9407) & JNF, LMF, CASA \\
\hline 53 & São João da Baliza & Rio dos Peixes. Km 36. Sitio 3 irmãos. Vicinal-26 (0,73325; -60,1803) & JNF, LMF, CASA \\
\hline 54 & São João da Baliza & Igarapé do Sítio Jaí. Vicinal-26. Km 30 (0,715944; -60,1909) & JNF, LMF, CASA \\
\hline 55 & São João da Baliza & Igarapé da $1^{a}$ ponte da Vicinal-26 $(0,9325 ;-59,9196)$ & JNF, LMF, CASA \\
\hline 56 & Caroebe & Rio Caroébe. Vicinal-37. Fazenda Iguacú $(0,952083 ;-59,617)$ & JNF, LMF, CASA \\
\hline 57 & São João da Baliza & Igarapé da Fazenda Coelho do Sul. Km 13. Vicinal-28 $(0,847028 ;-59,9398)$ & JNF, LMF, CASA \\
\hline 58 & São João da Baliza & Igarapé da $2^{a}$ ponte. Vicinal-28. Km $02(0,927056 ;-59,8747)$ & JNF, LMF, CASA \\
\hline 59 & Caroebe & Igarapé da última ponte da Vicinal-02 $(0,656861 ;-59,8413)$ & JNF, LMF, CASA \\
\hline 60 & Caroebe & Igarapé da Fazenda do Sr. Agel. Vicinal-02 $(0,824583 ;-59,7038)$ & JNF, LMF, CASA \\
\hline 61 & Caroebe & Igarapé Jacundá. $1^{\text {a }}$ ponte da Vicinal-02 $(0,849944 ;-59,6801)$ & JNF, LMF, CASA \\
\hline 62 & Caroebe & Igarapé Palmeirão. Última ponte da Vicinal-05 $(1,0165 ;-59,5751)$ & JNF, LMF, CASA \\
\hline 63 & Caroebe & Afluente do Rio Caroebe. Vicinal-05 (0,913056; -59,5727) & JNF, LMF, CASA \\
\hline 64 & Caroebe & Igarapé do Tabocal. BR-210 $(0,895417 ;-59,7353)$ & JNF, LMF, CASA \\
\hline 65 & Caroebe & Igarapé Baínha Podre. Sítio São Luís. Vicinal-08. Km 09 (0,751083; -59,5847) & JNF, LMF, CASA \\
\hline 66 & Caroebe & Rio Caroébe. Ramal $32(0,806778 ;-59,8534)$ & JNF, LMF, CASA \\
\hline
\end{tabular}




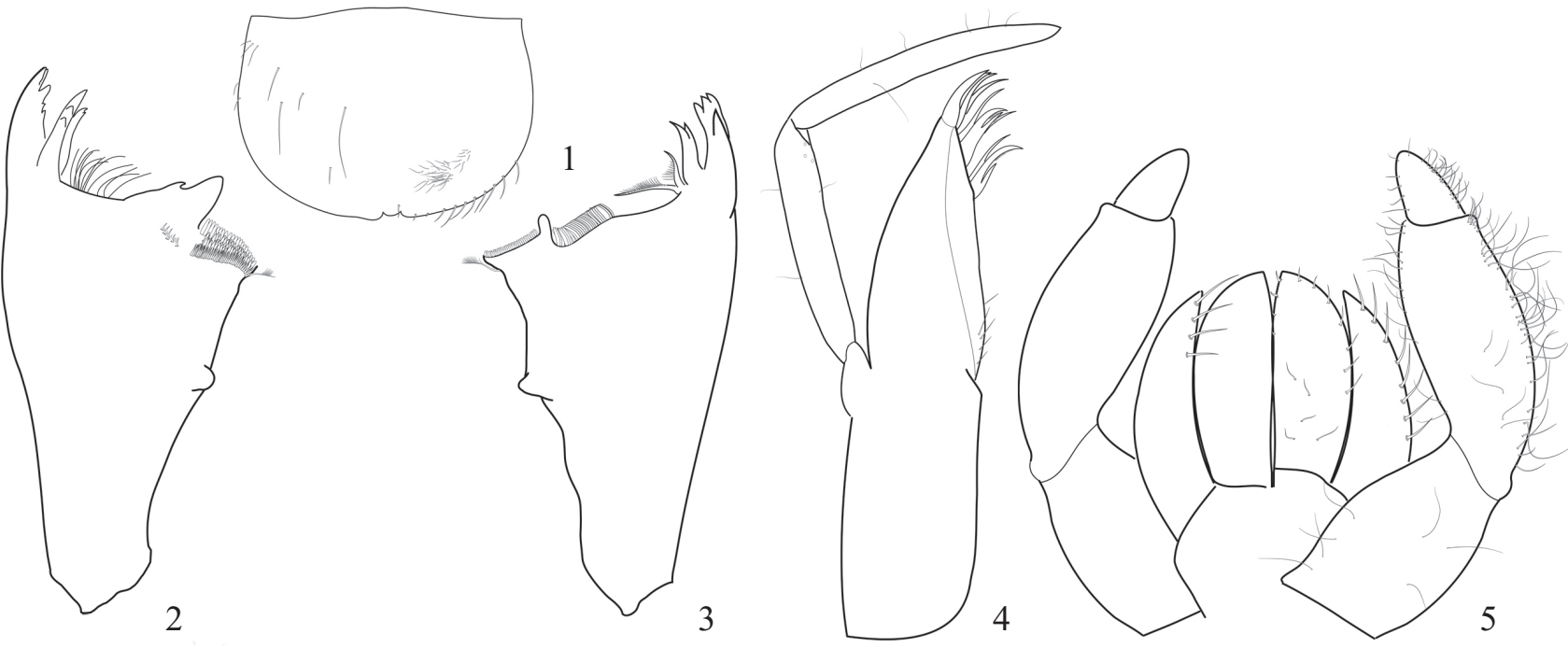

Figs. 1-5. Adebrotus amazonicus Lugo-Ortiz \& McCafferty, 1995 (modificada de Salles, 2010). 1.Llabro. 2. Mandíbula esquerda. 3. Mandíbula direita. 4. lábio. 5. Maxila.

\section{RESULTADOS}

\section{Adebrotus amazonicus Lugo-Ortiz \& McCafferty, 1995}

(Figs. 1-5)

Comentários: Adebrotus Lugo-Ortiz \& McCafferty, 1995 possui atualmente duas espécies, representadas ao todo por apenas seis indivíduos. Uma das espécies, A amazonicus, foi registrada para o Amazonas e Mato Grosso e a outra, $A$. lugoi Salles, 2010, para o sudeste do Brasil (Salles 2010). Uma espécie não determinada também foi registrada para a Guiana Francesa (Orth et al. 2000). Apesar do estado de Roraima estar situado dentro de uma possível área de distribuição do gênero, o baixo número de indivíduos conhecidos, com relatos pontuais, torna este registro uma importante contribuição para o conhecimento a respeito da distribuição do gênero. Além disso, a espécie $A$. amazonicus é reportada aqui ao norte de sua localidade-tipo pela primeira vez.

Material examinado: PT 05: (1) 22.iii.2001

\section{Americabaetis alphus Lugo-Ortiz \& McCafferty, 1996}

(Figs. 6-13)

Comentários: Provavelmente a espécie de Ephemeroptera de distribuição mais ampla na América do Sul, estando registrada para diversos estados brasileiros inlcuindo o Amazonas, na Região Norte (Salles et al. 2010b). Neste trabalho, esta espécie ocorreu em mais de $80 \%$ dos pontos amostrados e representou aproximadamente $40 \%$ dos indivíduos analisados.

Material examinado (1236): PT 01: (4) 03.xi.2006; PT 02: (22) 03.xi.2006; PT 04: (5) 04.xi.2006; PT 05: (24) 22.iii.2001, (8) 20.x.2004,
(9) 04.xi.2006, (43) 04.ii.2007; PT 06: (1) 05.xi.2006; PT 07: (23) 06.xi.2006; PT 09: (9) 07.xi.2006; PT 10: (18) 08.xi.2006; PT 12: (14) 09.xi.2006; PT 13: (5) 09.xi.2006; PT 14: (10) 09.xi.2006; PT 15: (9) 10.xi.2006; PT 16: (14) 10.xi.2006, (7) 03.ii.2007; PT 17: (2) 11.xi.2006, (1) 06.ii.2007; PT 18: (16) 13.xi.2006; PT 20: (7) 14.xi.2006; PT 22: (5) 15.xi.2006; PT 23: (1) 15.xi.2006; PT 24: (27) 15.xi.2006; PT 25: (54) 16.xi.2006; PT 26: (110) 16.xi.2006, (6) 06.ii.2007; PT 27: (25) 16.xi.2006; PT 28: (14) 17.xi.2006; PT 29: (5) 17.xi.2006; PT 30: (2) 01.iii.2003, (1) 03.ii.2007; PT 31: (8) 21.x.2004; PT 32: (10) 13.xii.2000, (4) 20.iii.2001, (3) 24.x.2001, (2N) 22.x.2004; PT 33: (38) 22.x.2004; PT 35: (1) 24.x.2004, (1) 05.ii.2007; PT 36: (4) 19.x.2004; PT 42: (13) 18.x.2004, (5) 09.ii.2007; PT 43: (7) 21.xi.2006, (1) 12.ii.2007; PT 44: (30) 21.xi.2006; PT 45: (4) 22.xi.2006; PT 46: (53) 23.xi.2006; PT 47: (61) 24.xi.2006; PT 48: (23) 24.xi.2006; PT 49: (61) 24.xi.2006; PT 50: (35) 25.xi.2006; PT 51: (71) 25.xi.2006; PT 52: (45) 25.xi.2006; PT 53: (6) 26.xi.2006; PT 54: (72) 26.xi.2006; PT 55: (27) 26.xi.2006; PT 56: (18) 27.xi.2006, (1) 13.ii.2007; PT 57: (18) 28.xi.2006; PT 59: (15) 29.xi.2006; PT 60: (28) 29.xi.2006; PT 61: (3) 29.xi.2006; PT 62: (27) 30.xi.2006; PT 63: (3) 30.xi.2006; PT 64: (3) 30.xi.2006; PT 65: (3) 01.xii.2006, (1) 11.ii.2007; PT 66: (27) 14.ii.2007.

\section{Apobaetis fiuzai Salles \& Lugo-Ortiz, 2002}

(Figs. 14-20)

Comentários: Apobaetis Day, 1955, atualmente com apenas três espécies para o Brasil (Salles \& Lugo-Ortiz 2002a, Cruz et al. 2011), já havia sido reportado para a Região Norte com a espécie $A$. signifer Lugo-Ortiz \& McCafferty, 1997 para o Pará (Lugo-Ortiz \& McCafferty 1997). Recentemente foi registrado também para o Amazonas com as espécies A. fiuzai e Apobaetis hamadae Cruz, Boldrini \& Salles, 2011 (Cruz et al. 2011). Apobaetis fiuzai, registrada também para as Regiões Sudeste e Centro-Oeste do Brasil e para a Argentina (Nieto 2006), tem sua distribuição estendida ao norte da América do Sul

Material examinado (5): PT 05: (3) 04.xi.2006; PT 08: (1) 07.xi.2006; PT 61: (1) 29.xi.2006. 

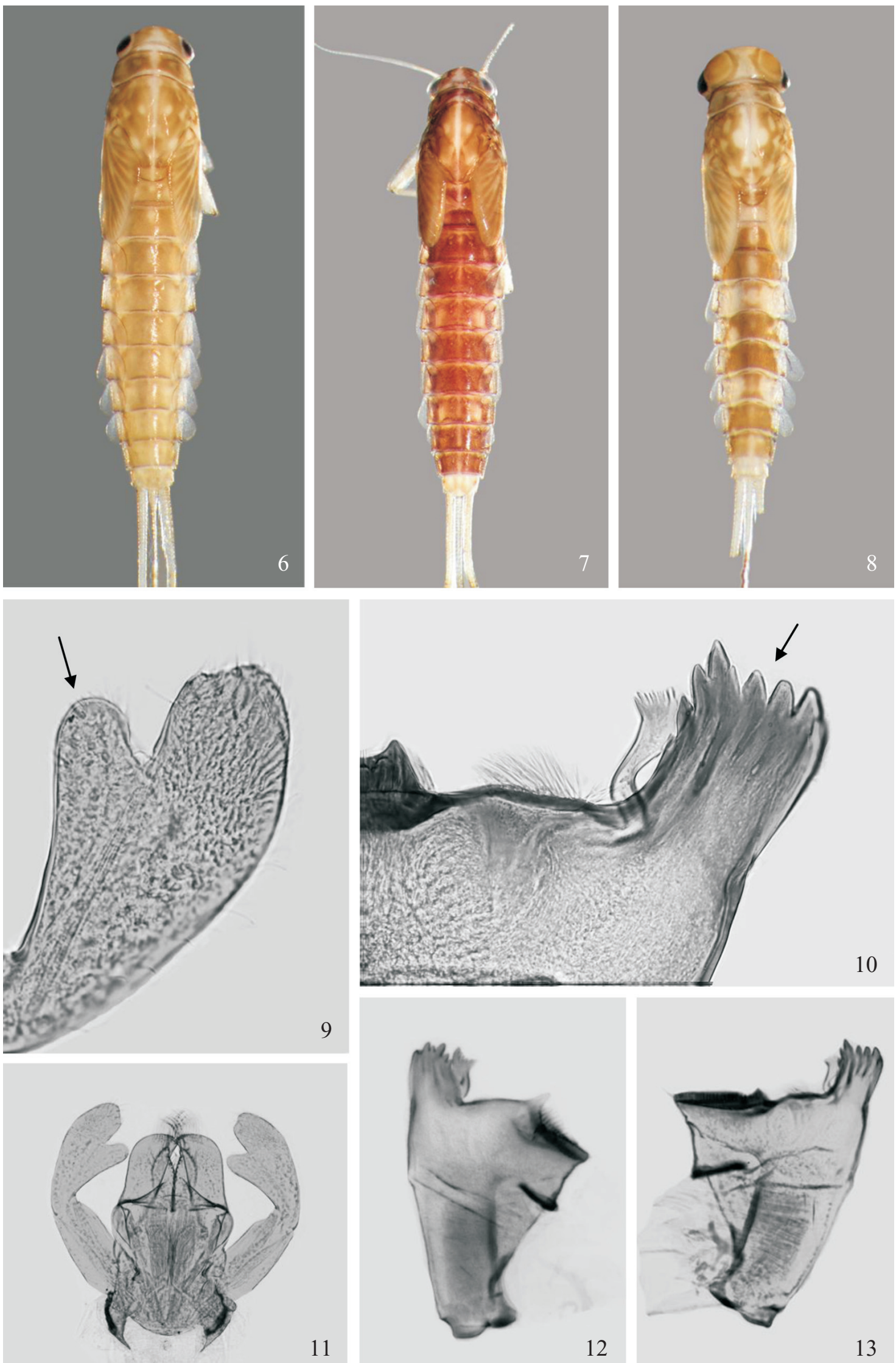

Figs. 6-13. Americabaetis alphus Lugo-Ortiz \& McCafferty, 1996. 6-8. Vista dorsal (6 e 7 - o; 8 - O'). 9. Palpo labial. 10. Detalhe da mandíbula direita. 11. Lábio. 12. Mandíbula esquerda. 13. Mandíbula direita. 

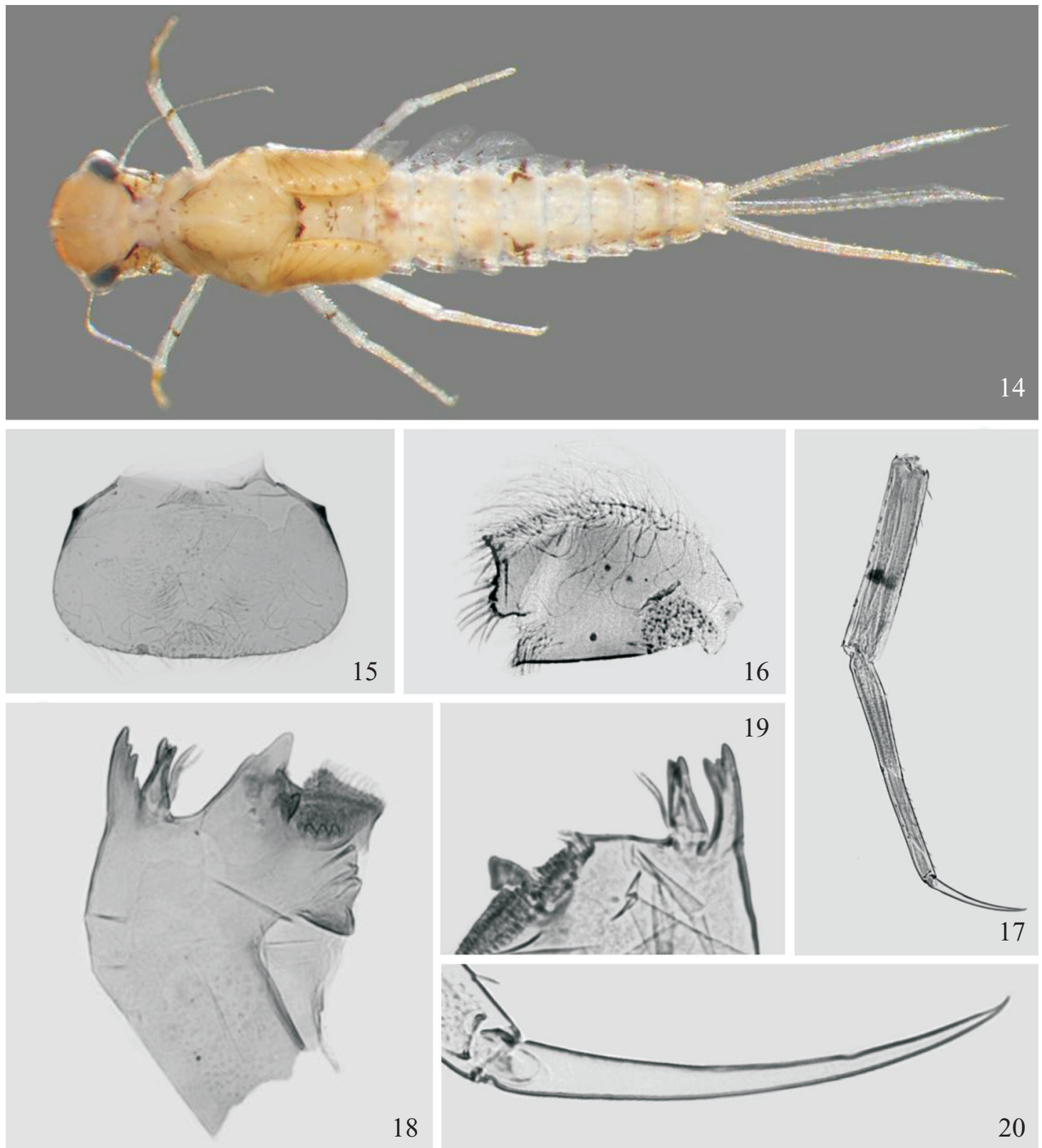

Figs. 14-20. Apobaetis fiuzai Salles \& Lugo-Ortiz, 2002. 14. Vista dorsal (ơ). 15. Labro. 16. Palpo labial. 17. Perna. 18. Mandíbula esquerda. 19. Detalhe da mandíbula direita. 20. Garra tarsal.

\section{Aturbina georgei Lugo-Ortiz \& McCafferty, 1996}

(Figs. 21-27)

Comentários: Apresenta uma ampla distribuição sul-americana, podendo ser encontrada em diversos estados brasileiros. Na Região Norte, havia sido previamente reportada para os estados do Amazonas e Pará (Salles et al. 2004b, Salles et al. 2011b), com ocorrência esperada para o estado de Roraima. Este novo registro vem ampliar a sua documentação na região.

Material examinado (143): PT 01: (2) 03.xi.2006; PT 05: (3) 04.xi.2006; PT 06: (1) 05.xi.2006; PT 15: (7) 19.x.2004, (3) 10.xi.2006; PT 24: (1) 15.xi.2006; PT 29: (14) 17.xi.2006; PT 32: (1) 22.x.2004; PT 33: (1) 22.x.2004; PT 39: (2)21.x.2004; PT 43: (3) 21.xi.2006; PT 46: (1) 23.xi.2006; PT 48: (3) 24.xi.2006; PT 49: (5) 24.xi.2006; PT 57: (2) 12.ii.2007; PT 59: (11) 29.xi.2006, (1) 14.ii.2007; PT 60: (9) 29.xi.2006; PT 61: (21) 29.xi.2006; PT 62: (17) 30.xi.2006; PT 64: (31) 30.xi.2006; PT 66: (4) 14.ii.2007.

\section{Aturbina nigra Salles, Boldrini \& Shimano, 2011}

(Figs. 28-29)

Comentários: Uma das poucas espécies do presente trabalho previamente registradas para o estado, fato ocorrido recentemente a partir de sua descrição (Salles et al. 2011b).

Material examinado (5): PT 12: (1) 09.xi.2006; PT 32: (1) 20.iii.2001; PT 33: (1) 22.x.2004; PT 46: (1) 23.xi.2006.

Revista Brasileira de Entomologia 55(4): 516-548, dezembro, 2011 

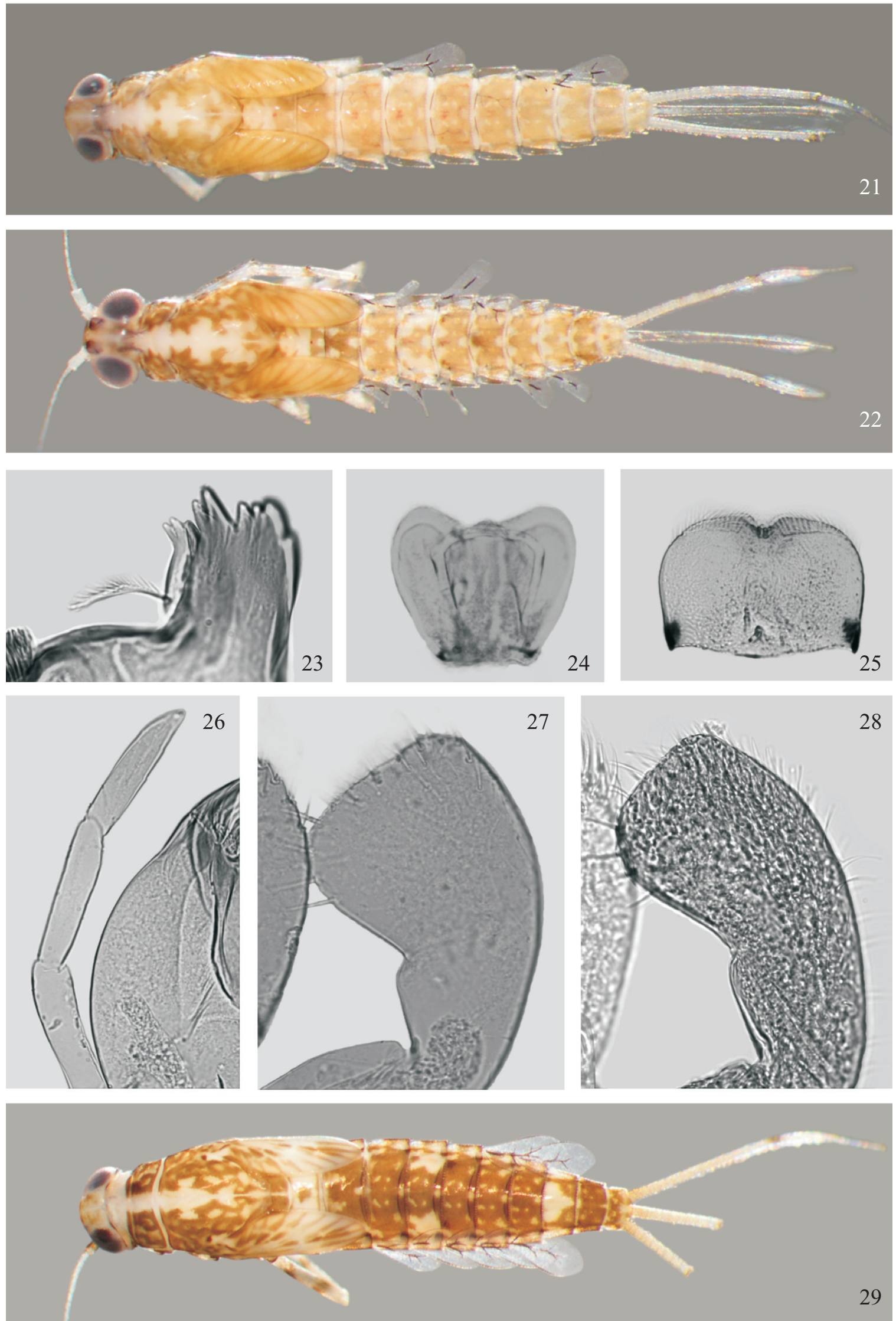

Figs. 21-29. Aturbina georgei Lugo-Ortiz \& McCafferty, 1996 (22-27). 21 e 22. Vista dorsal (21 - ९; 22 - ơ). 23. Detalhe da mandíbula direita. 24. Hipofaringe. 25. Labro. 26. Palpo maxilar. 27. Palpo labial. Aturbina nigra Salles, Boldrini \& Shimano, 2011 (28-29). 28. Palpo labial. 29. Vista dorsal (O). 


\section{Baetodes cf. proiectus Mayo, 1973}

(Figs. 30-36)

Comentários: Baetodes Needham \& Murphy, 1924 está entre os mais diversos da Região Neotropical, atualmente com 27 espécies sul-americanas (Nieto 2004; Salles \& Polegatto 2008; Souza et al. no prelo). Entretanto, no Brasil, o gênero é representado por somente sete espécies, descritas a partir de exemplares coletados nas regiões Sul e Sudeste do país. No presente estudo, o gênero é registrado pela primeira vez na Região Norte. Baetodes proiectus foi descrita para a Bolívia e até o presente não foi reportada para outra localidade (Mayo 1973). A descrição dessa espécie é antiga e incompleta, não sendo possível afirmar se os indivíduos coletados pertencem a $B$. proiectus ou se tratam de uma nova espécie sem a consulta ao material-tipo.
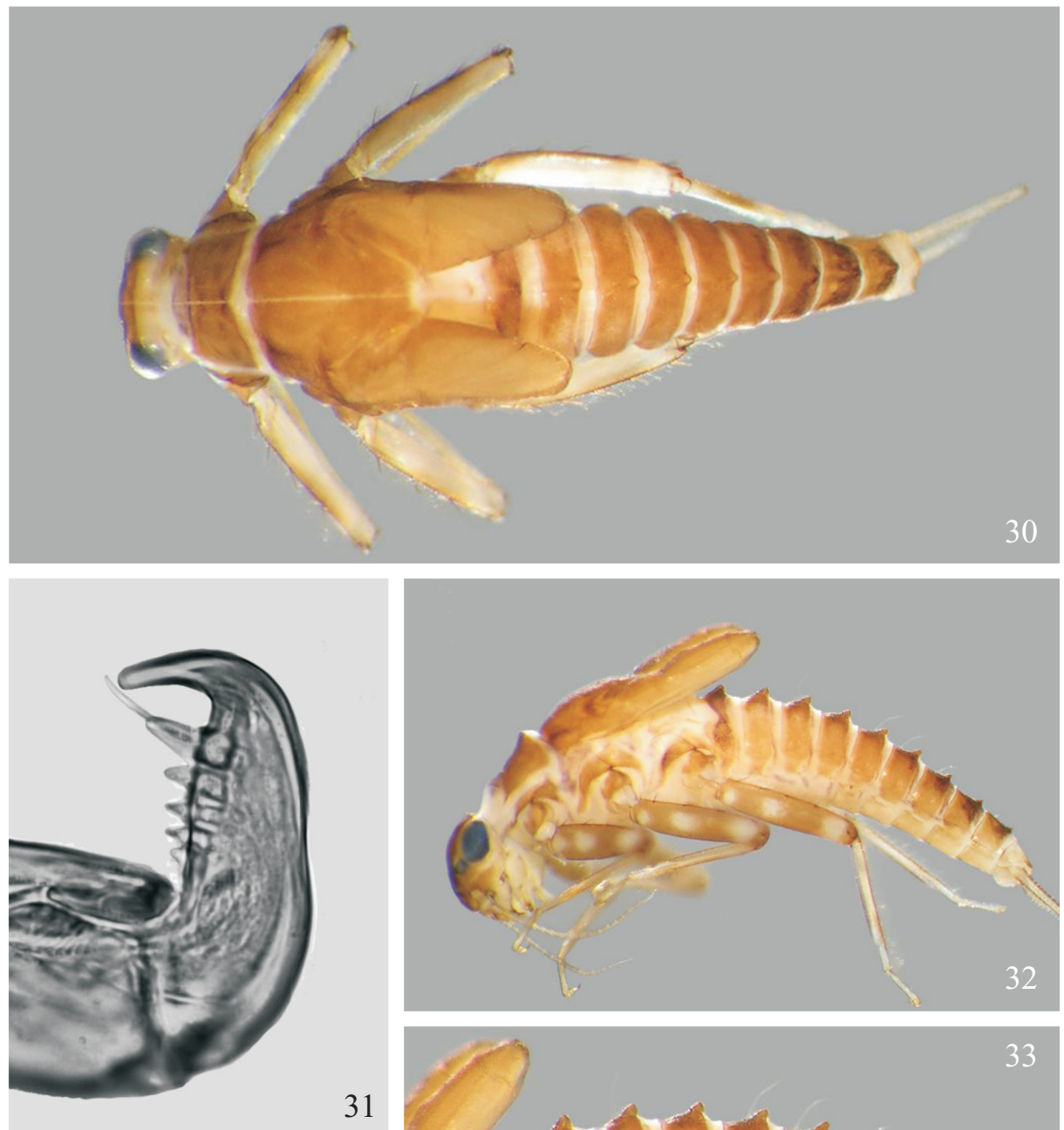

31
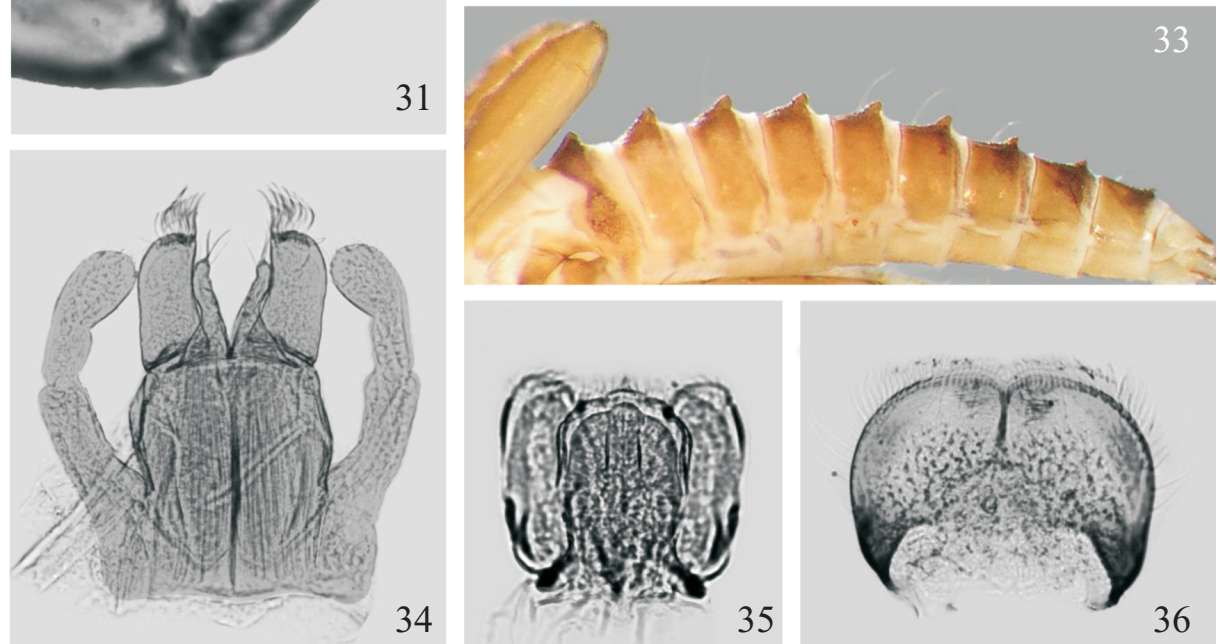

Figs. 30-36. Baetodes cf. proiectus Mayo, 1973. 30. Vista dorsal (@). 31. Garra tarsal. 32. Vista lateral. 33. Detalhe dos tubérculos abdominais. 34. Lábio. 35. Hipofaringe. 36. Labro. 
Material examinado (9): PT 17: (1) 11.xi.2006; PT 32: (2) 13.xii.2000, (6) 22.x.2004

\section{Callibaetis Eaton, 1881}

(Figs. 37-42)

Comentários: Callibaetis representa uma exceção dentro da família, com todas as espécies descritas a partir das formas aladas e poucas conhecidas no estágio ninfal. Neste tra- balho foram encontradas duas espécies de Callibaetis, que não conferem com nenhuma das descrições de ninfas existentes, não sendo possível até o momento afirmar se estas se tratam de novas espécies ou de ninfas de espécies conhecidas apenas pelos adultos.

Material examinado (32): PT 01: (6) 03.xi.2006; PT 05: (3) 04.xi.2006; PT 13: (11) 09.xi.2006; PT 14: (1) 09.xi.2006; PT 21: (1) 14.xi.2006; PT 22: (3) 15.xi.2006; PT 29: (2) 17.xi.2006; PT 36: (1) 19.x.2004: PT 39: (1) 21.x.2004; PT 43: (1) 12.ii.2007; PT 49: (1) 24.xi.2006; PT 61: (1) 20.xi.2006.
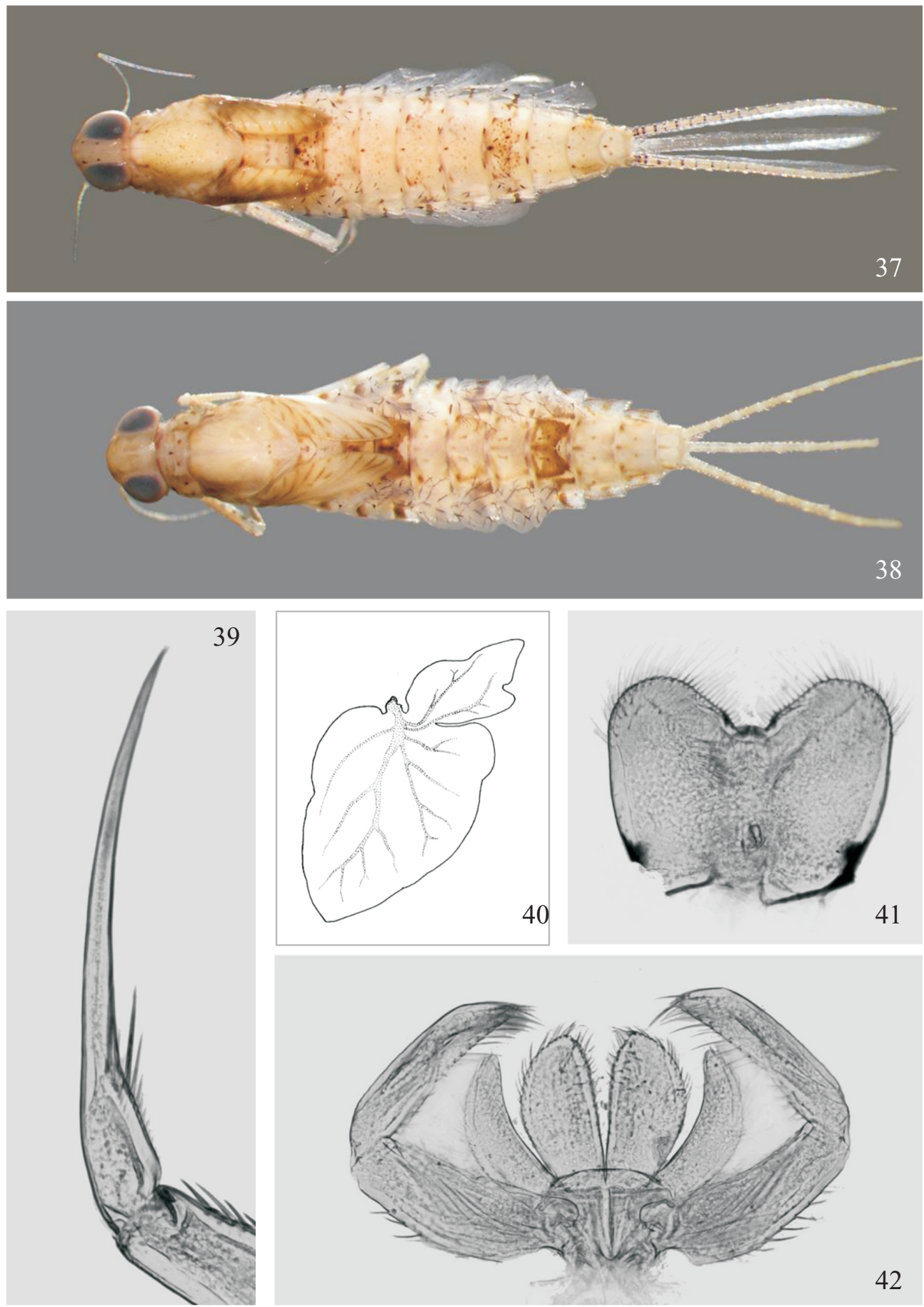

40

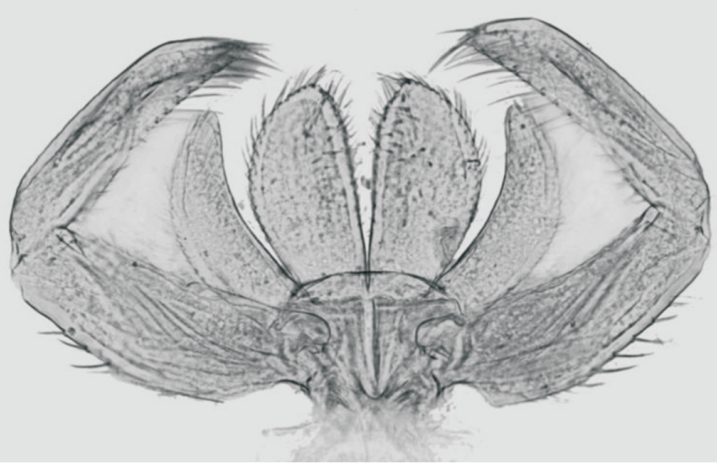

Figs. 37-42. Callibaetis Eaton, 1881. 37 e 38. Vista dorsal (@). 39. Garra tarsal anterior. 40. Brânquia (retirada de Salles, 2006). 41. Labro. 42. Lábio. 


\section{Camelobaetidius anubis (Traver \& Edmunds, 1968)}

(Figs. 43-47)

Comentários: Camelobaetidius anubis, que se encontrava previamente relatada no Brasil para as regiões Sul e Sudeste (Salles \& Serrão 2005; Boldrini \& Salles 2009), é registrada para a Região Norte pela primeira vez, expandindo sua distribuição para o norte da América do Sul. Os exemplares coletados apresentaram divergência quanto ao número de dentículos da garra (35 dentículos), quando comparado com a descrição original (20 a 27 dentículos). No entanto, essa variação está sendo considerada uma variação intraespecífica, uma vez que não foram observadas outras variações significativas com relação à descrição da espécie.
Material examinado (7): PT 30: (1) 01.iii.2003; PT 31: (3) 12.xii.2000; PT 32: (3) 22.x.2004.

\section{Camelobaetidius billi Thomas \& Dominique, 2000}

(Figs. 48-55)

Comentários: Descrita para Guiana Francesa e registrada para o Brasil (Salles \& Dias 2004) através de exemplares do Amazonas, constituindo o único relato da espécie após a sua descrição. A nova ocorrência para Roraima contribui com o conhecimento sobre a distribuição da espécie, indicando que a falta de registros se deve a carência de coletas na América do Sul.

Material examinado (34): PT 27: (2) 16.xi.2006; PT 31: (5) 12.xii.2000; PT 32: (18) 22.x.2004; PT 33: (1) 22.x.2004; PT 34: (3) 13.xii.2000; PT 65: (6) 01.xii.2006
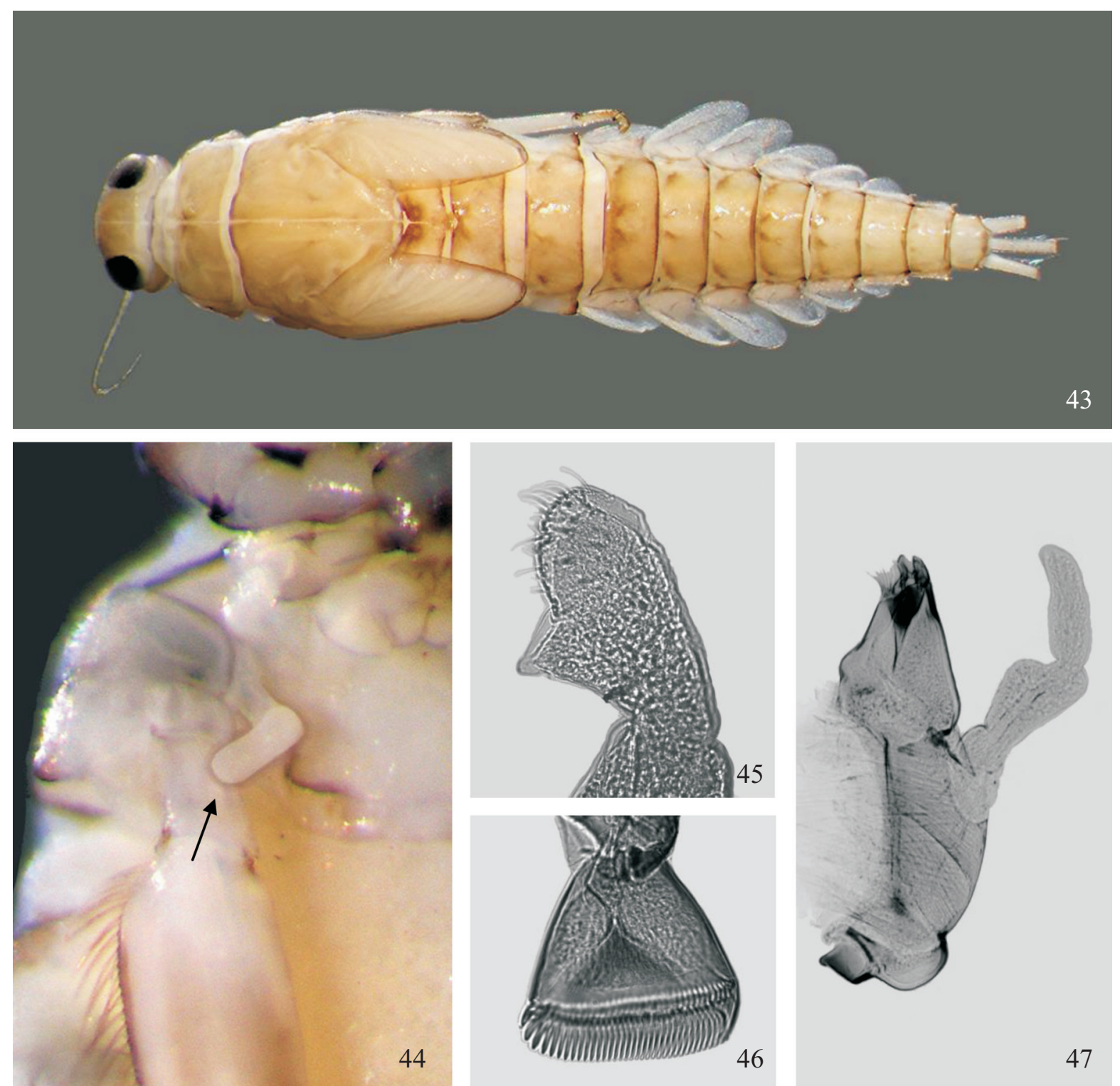

Figs. 43-47. Camelobaetidius anubis (Traver \& Edmunds, 1968). 43. Vista dorsal (Q). 44. Brânquia da base da coxa. 45. Palpo labial. 46. Garra tarsal. 47. Maxila. 

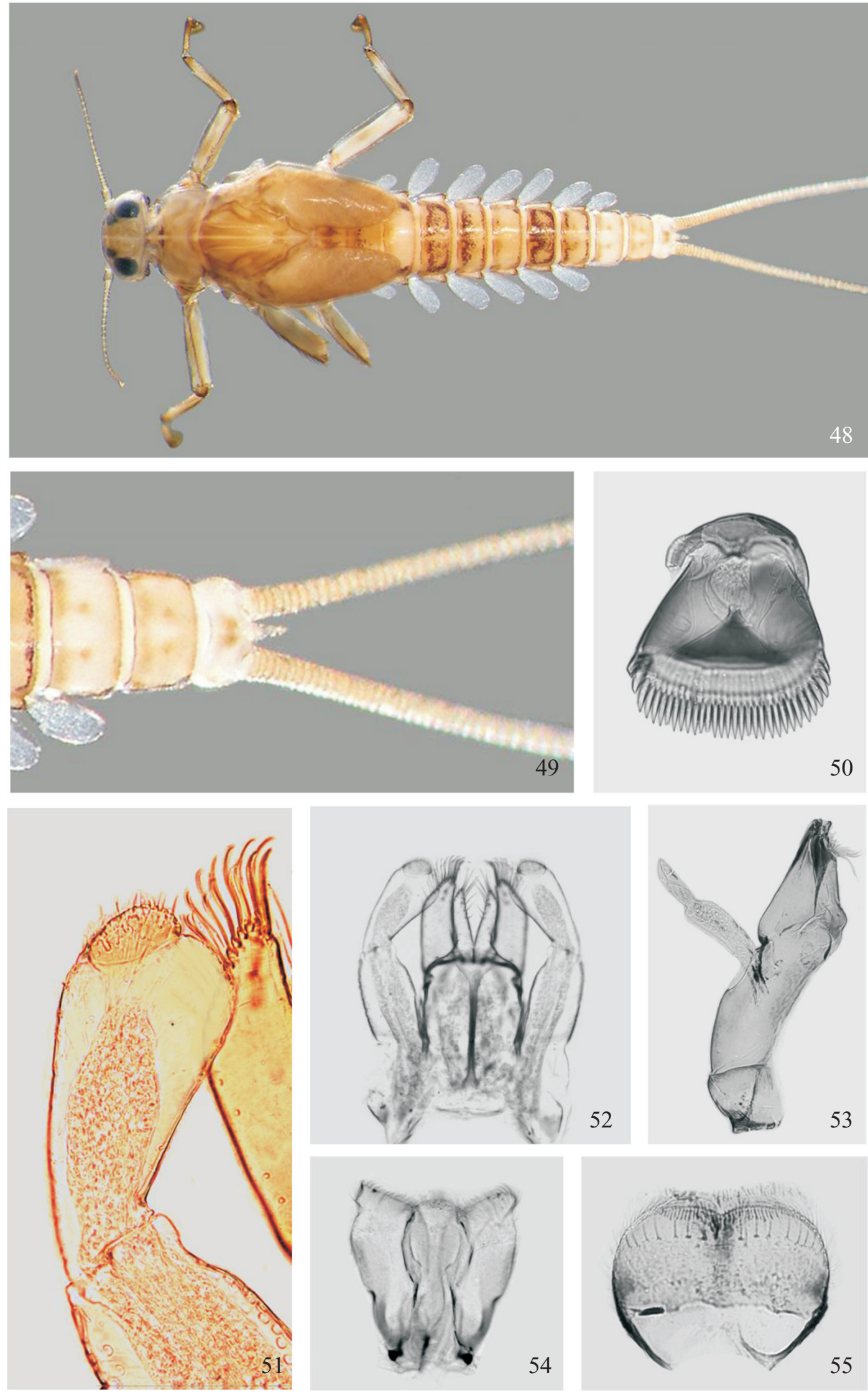

52
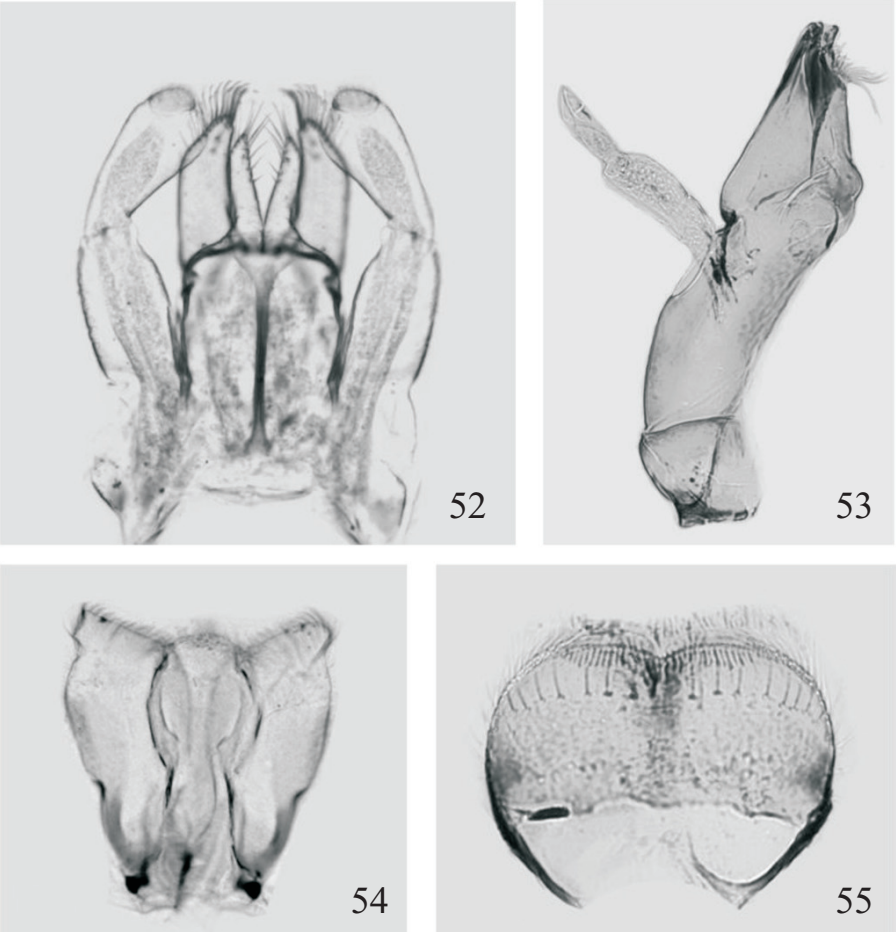

Figs. 48-55. Camelobaetidius billi Thomas \& Dominique, 2000. 48. Vista dorsal (o). 49. Detalhe dos filamentos caudais. 50. Garra tarsal. 51. Palpo labial. 52. Lábio. 53. Maxila. 54. Hipofaringe. 55. Labro. 


\section{Camelobaetidius cayumba (Traver \& Edmunds, 1968)}

(Figs. 56-60)

Comentários: Descrita para o Peru (Traver \& Edmunds 1968) e encontra-se registrada para a Guiana Francesa (Thomas et al. 2003) e para os estados de Goiás e Rondônia no Brasil (Salles \& Serrão 2005). Os indivíduos coletados apresentaram algumas diferenças com relação à descrição, sendo maiores, com 4,6mm, com maior número de dentículos nas garras, de 21 a 23, e maior número de espinhos no paraprocto, com sete. Como no momento tais diferenças não justificam a descrição de uma nova espécie, os exemplares foram considerados uma variação de C. cayumba.

Material examinado (97): PT 05: (3) 05.xi.2006, (11) 04.ii.2007; PT 30: (1) 22.iii.2002, (1) 03.ii.2007; PT 32: (1) 22.x.2004; PT 43: (3) 21.xi.2006; PT 54: (16) 26.xi.2006; PT 56: (9) 27.xi.2006, (13) 13.ii.2007; PT 59: (27) 29.xi.2006; PT 60: (1) 29.xi.2006; PT 61: (1) 29.xi.2006; PT 63: (2) 30.xi.2006; PT 65: (8) 01.xii.2006.
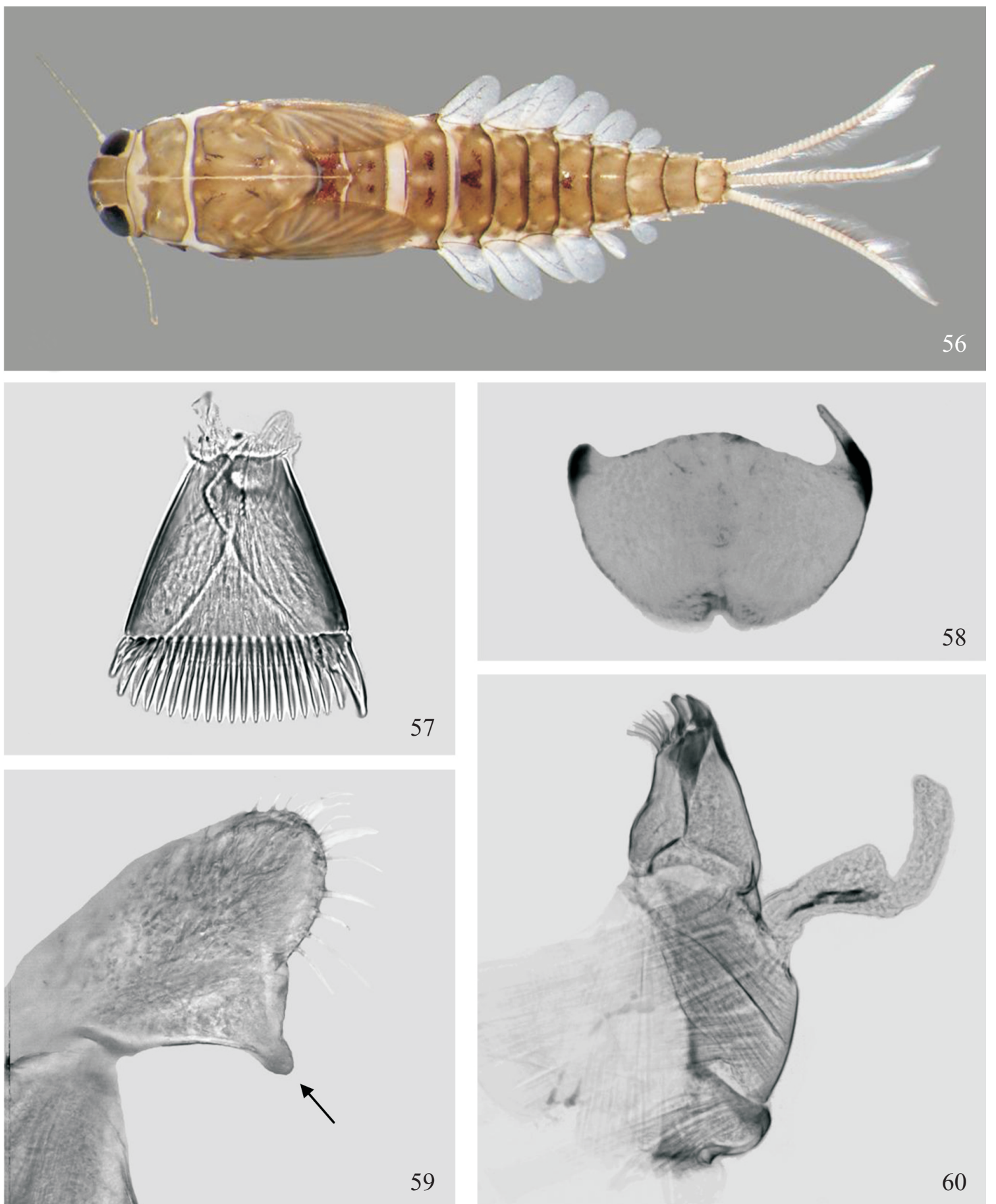

Figs. 56-60. Camelobaetidius cayumba (Traver \& Edmunds, 1968). 56. Vista dorsal (O)). 57. Garra tarsal. 58. Labro. 59. Palpo labial. 60. Maxila. 


\section{Camelobaetidius janae Dominique \& Thomas, 2000}

(Figs. 61-65)

Comentários: Encontra-se registrada no Brasil para os estados do Mato Grosso e Rondônia (Salles \& Serrão 2005). É importante ressaltar que nos indivíduos coletados foi observada uma grande variação quanto ao número de dentículos da garra. Um dos indivíduos apresentou entre 8 e 9 dentículos na garra (PT 54), enquanto o restante apresentou cerca de 25 dentículos. Apesar dessa grande variação, não foram obser- vadas outras diferenças significativas entre os exemplares, sendo considerada aqui como uma variação intraespecífica.

Material examinado (143): PT 05: (3) 20.x.2004, (3) 04.ii.2007; PT 27: (2) 16.xi.2006; PT 28: (1) 17.xi.2006; PT 29: (1) 17.xi.2006; PT 30: (1) 24.x.2001; PT 35: (4) 24.x.2004; PT 36: (1) 19.x.2004; PT 38: (3) 23.iii.2002; PT 40: (1) 22.iii.2002; PT 42: (3) 23.iii.2001, (3) 23.x.2001, (14) 18.x.2004, (5) 09.ii.2007; PT 43: (5) 12.ii.2007; PT 43: (27) 21.xi.2006; PT 53: (17) 26.xi.2006; PT 54: (2) 26.xi.2006; PT 56: (1) 27.xi.2006, (2) 13.ii.2007; PT 59: (3) 29.xi.2006; PT 63: (1) 30.xi.2006; PT 65: (35) 01.xii.2006.
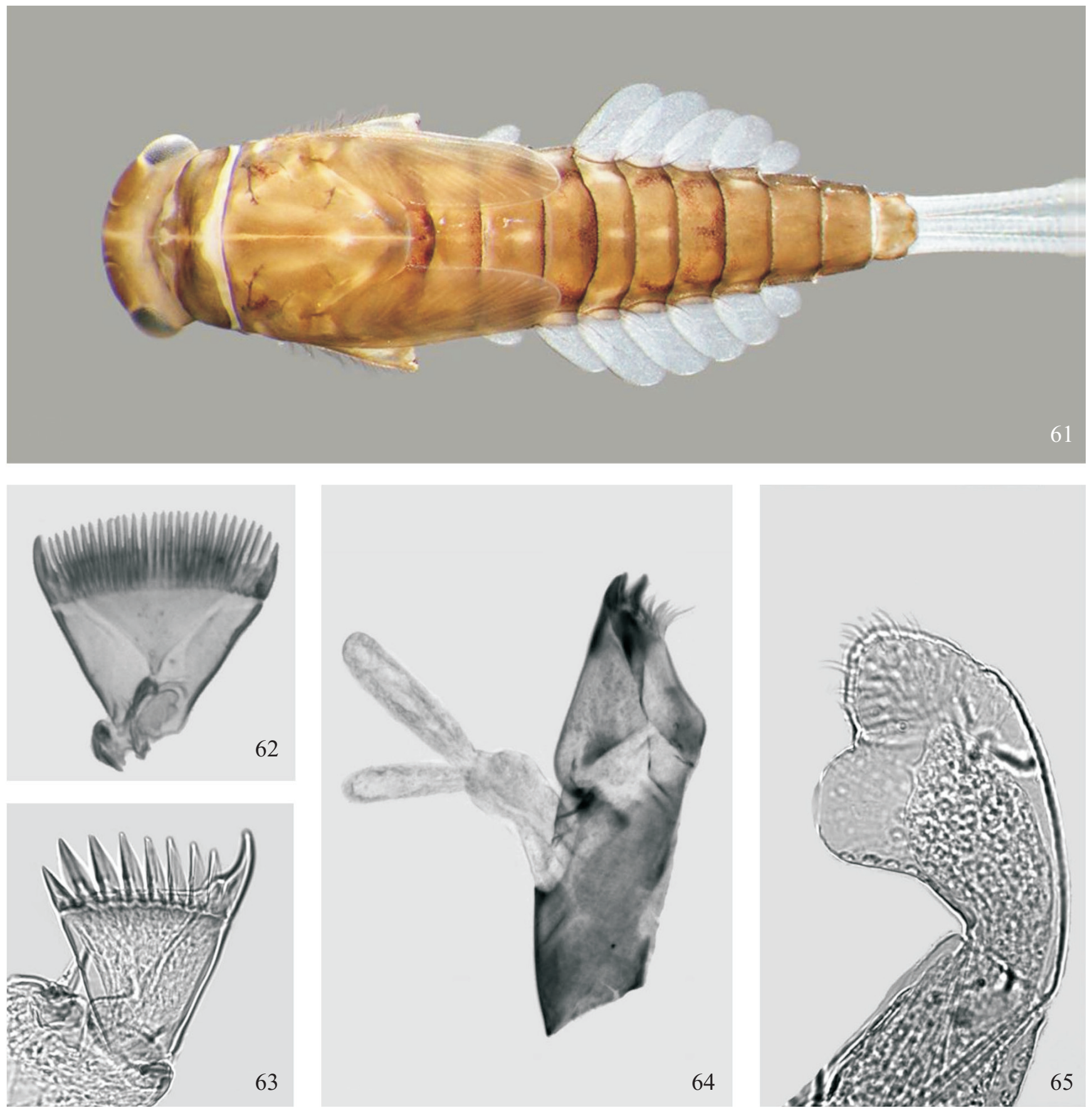

Figs. 61-65. Camelobaetidius janae Dominique \& Thomas, 2000. 61. Vista dorsal (o'). 62 e 63. Garra tarsal. 64. Maxila. 65. Palpo labial. 


\section{Camelobaetidius matilei Thomas \& Péru, 2003}

(Figs. 66-70)

Comentários: Descrita para a Guiana Francesa e reportada recentemente para o estado de Roraima (Salles \& Serrão
2005). Aqui é documentada sua ocorrência em outras localidades do estado, visando contribuir com o conhecimento sobre a distribuição da espécie.

Material examinado (7): PT 26: (1) 16.xi.2006; PT 30: (3) 24.x.2001; PT 32: (2) 22.x.2004; PT 65: (1) 01.xii.2006.
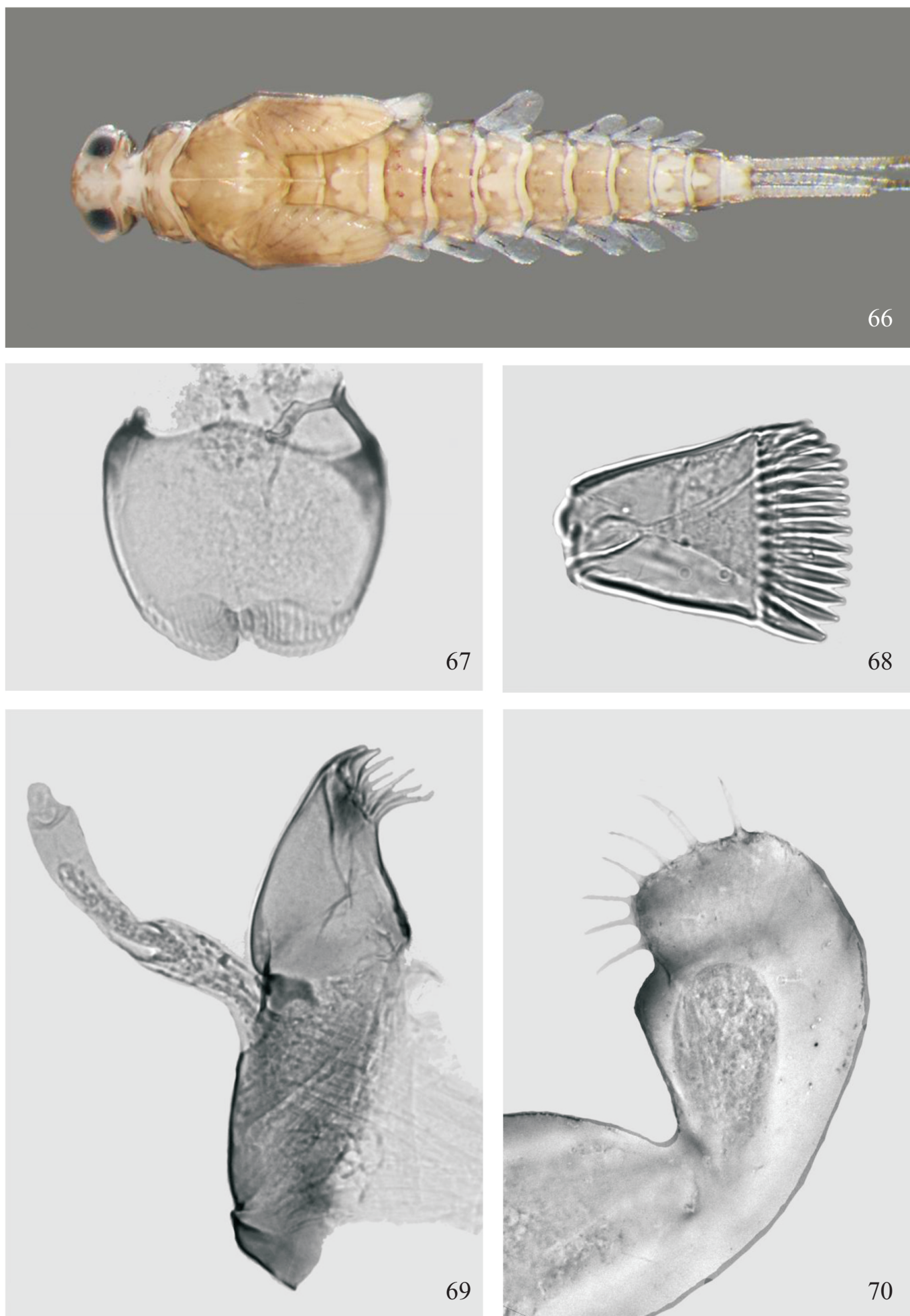

Figs. 66-70. Camelobaetidius matilei Thomas \& Péru, 2003. 66. Vista dorsal (\$). 67. Labro. 68. Garra tarsal. 69. Maxila. 70. Palpo labial. 
Camelobaetidius ortizi Dominique \& Thomas, 2002 (Figs. 71-75)

Comentários: Camelobaetiduis ortizi, assim como outras espécies do gênero apresentadas neste trabalho, foi descrita para a Guiana Francesa (Dominique \& Thomas 2002). Até o momento, havia sido registrada apenas para a sua localidadetipo, tornando este o primeiro registro da espécie para o Brasil.

Material examinado: PT 54: (2) 26.xi.2006; PT 59: (2) 29.xi.2006.
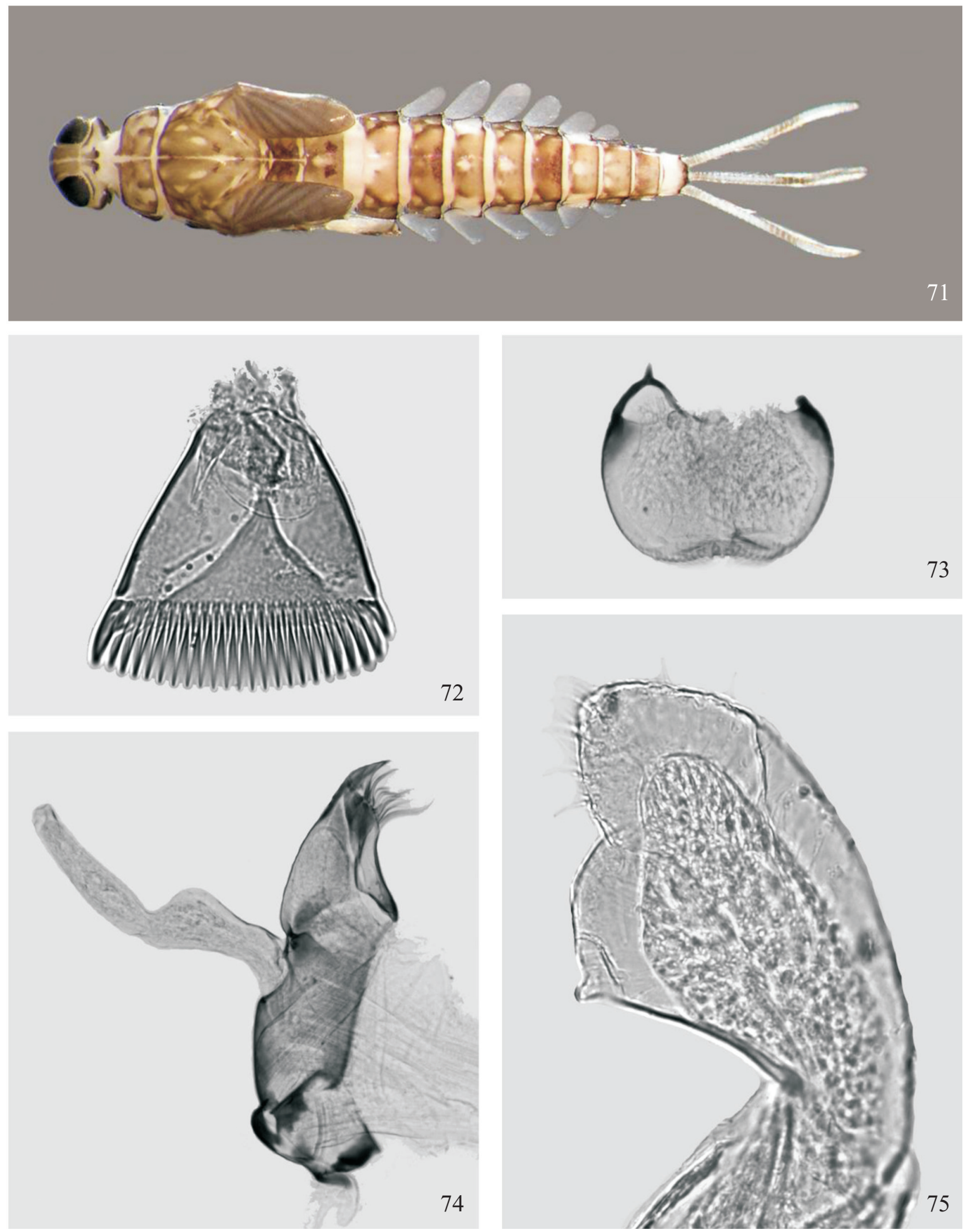

Figs. 71-75. Camelobaetidius ortizi Dominique \& Thomas, 2001. 71. Vista dorsal (Q). 72. Garra tarsal. 73. Labro. 74. Maxila. 75. Palpo labial. 


\section{Chane baure Nieto, 2003}

(Figs. 76-82)

Comentários: Descrita para a Bolívia (Nieto 2003) e reportada recentemente para o estado de Roraima (Salles 2007). Neste trabalho, ela foi coletada apenas na mesma localidade registrada anteriormente por Salles (2007).
Material examinado: PT 42: (3) 09.ii.2007.

\section{Cloeodes auwe Salles \& Batista, 2005}

(Figs. 83-88)

Comentários: Descrita recentemente para o estado do Mato Grosso (Salles et al. 2004a), a espécie é registrada aqui
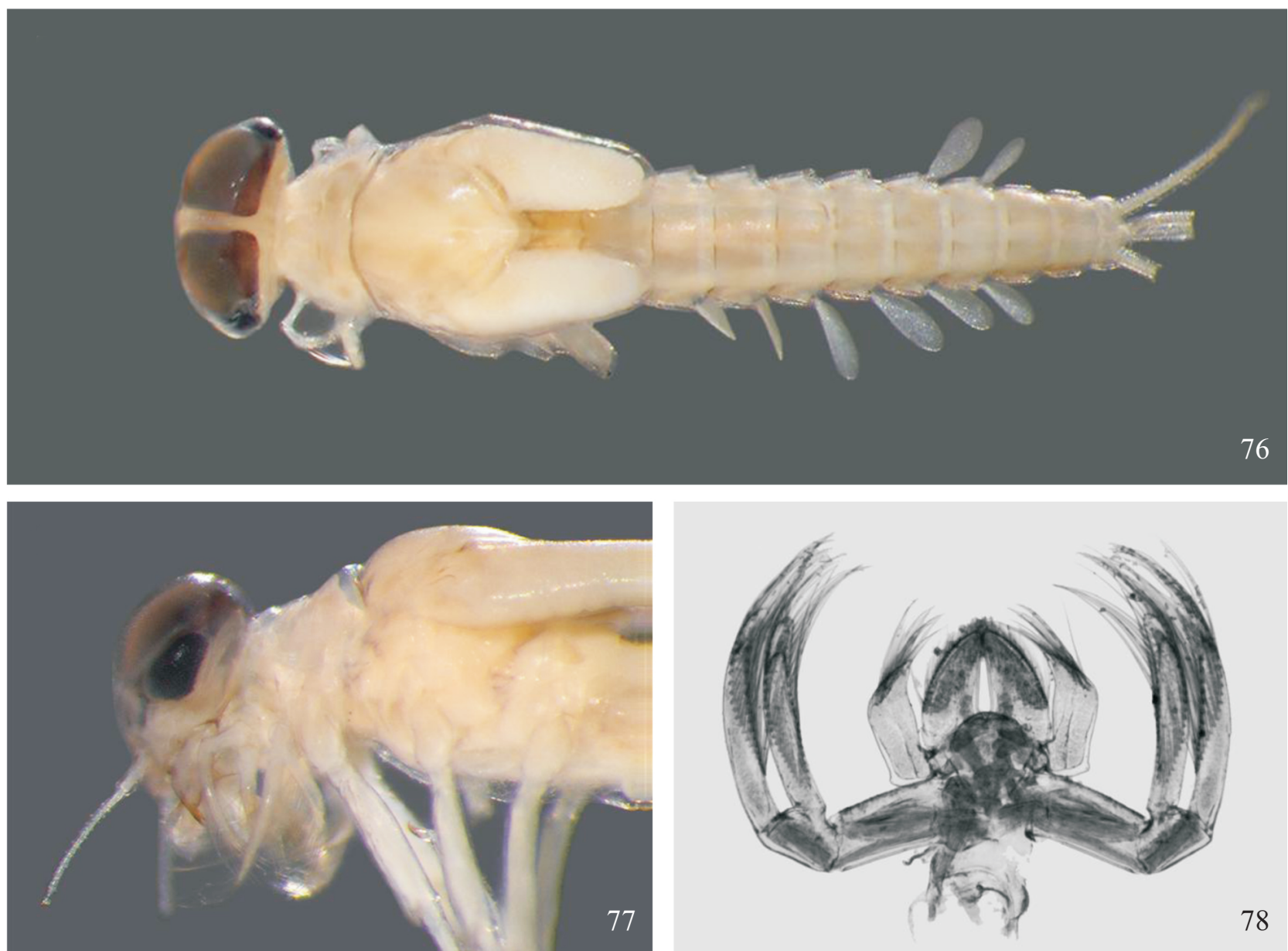

78
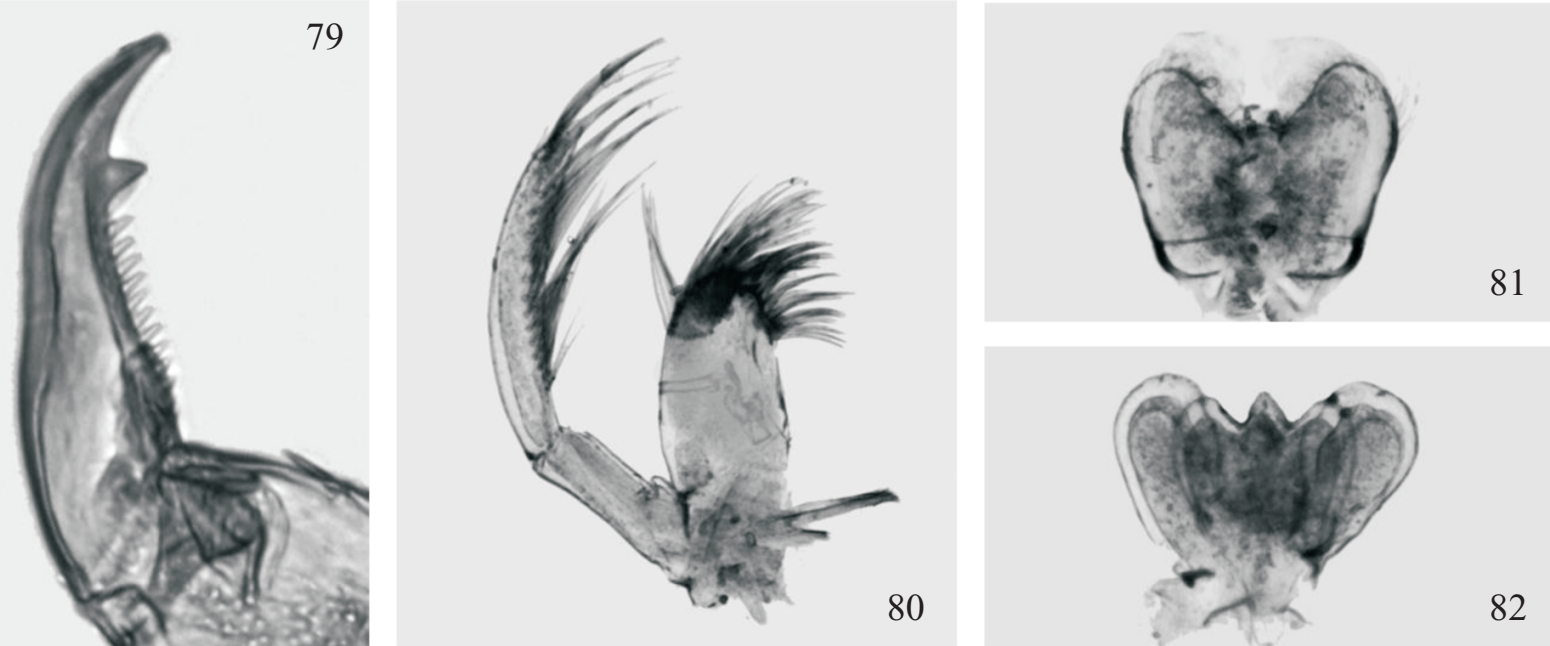

Figs. 76-82. Chane baure Nieto, 2003. 76. Vista dorsal (O゙). 77. Vista lateral da cabeça. 78. Lábio. 79. Garra tarsal. 80. Maxila. 81. Labro. 82. Hipofaringe. 
pela primeira vez em outro estado do Brasil. Esse registro amplia sua distribuição ao norte da América do Sul.

Material examinado (32): PT 05: (2) 04.xi.2006; PT 08: (1) 07.xi.2006; PT 16: (3) 10.xi.2006; PT 17: (1) 11.xi.2006; PT 24: (1) 15.xi.2006; PT 29: (3) 17.xi.2006; PT 30: (1) 24.x.2001; PT 39: (1) 21.x.2004; PT 43: (2) 21.xi.2006; PT 51: (1) 25.xi.2006; PT 52: (2) 25.xi.2006; PT 59: (5) 14.ii.2007; PT 60: (6) 29.xi.2006; PT 64: (3) 30.xi.2006.

\section{Cloeodes barituensis Nieto \& Richard, 2008}

(Figs. 89-90)

Comentários: Descrita recentemente para Argentina (Nieto \& Richard 2008), o novo registro para o estado de Roraima representa também o primeiro registro da espécie para o Brasil e estende consideravelmente ao norte a sua distribuição.
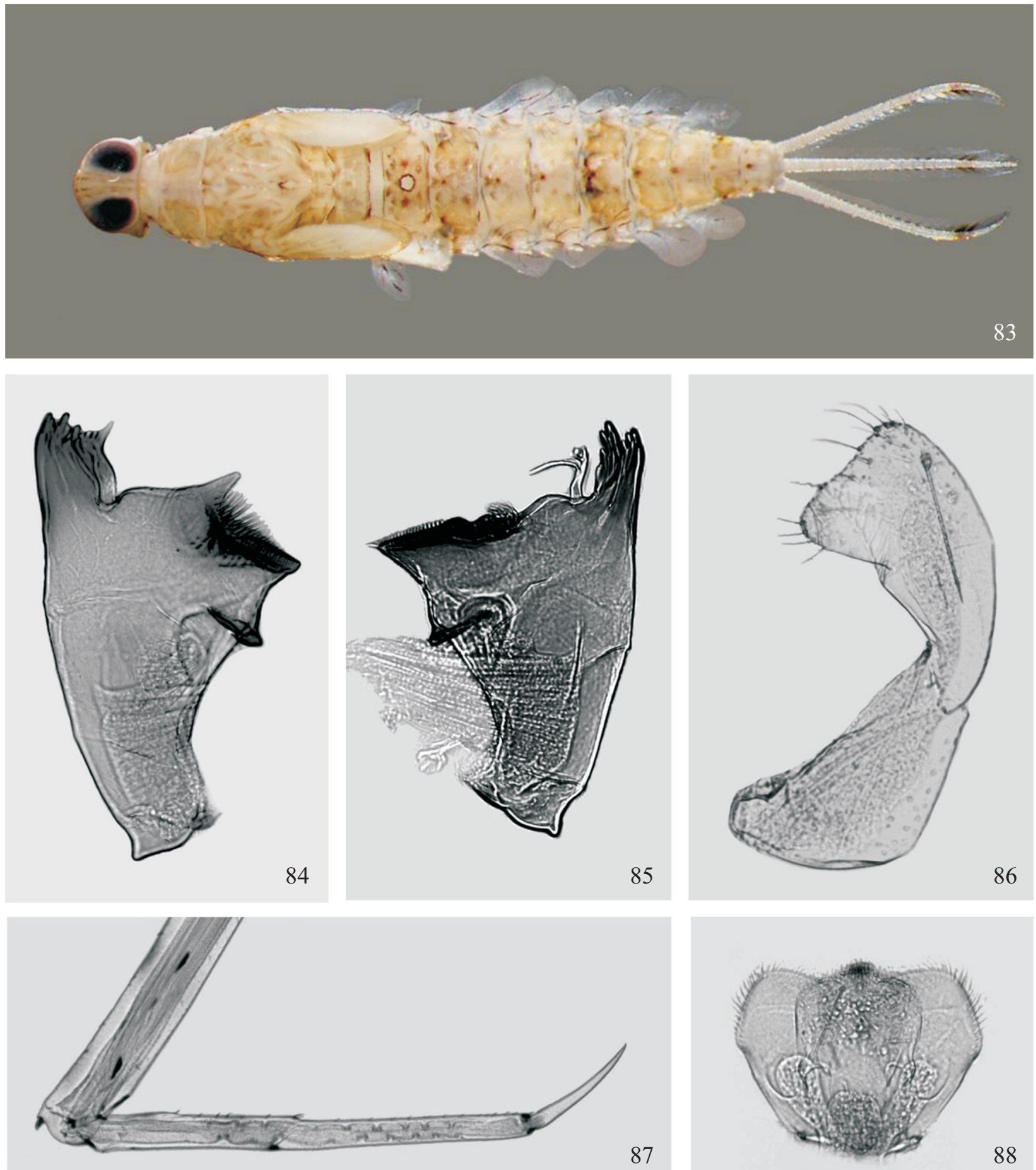

Figs. 83-88. Cloeodes auwe Salles \& Batista, 2005. 83. Vista dorsal (Q). 84. Mandíbula esquerda. 85. Mandíbula direita. 86. Palpo labial. 87. Perna. 88. Hipofaringe. 
Material examinado (22): PT 11: (2) 08.xi.2006; PT 27: (5) 16.xi.2006; PT 29: (2) 17.xi.2006; PT 32: (6) 20.iii.2001; PT 41: (1) 25.x.2001; PT 48: (1) 24.xi.2006; PT 56: (4) 27.xi.2006; PT 65: (1) 01.xii.2006.

\section{Cloeodes cf. hydation McCafferty \& Lugo-Ortiz, 1995}

(Figs. 91-93)

Comentários: Cloeodes hydation encontra-se registrada somente para os estados de Minas Gerais, Mato Grosso (Salles et al. 2004b) e Espírito Santo (Salles et al. 2010a). Os indivíduos coletados não apresentaram divergências com relação à descrição (McCafferty \& Lugo-Ortiz 1995), exceto que eles não apresentaram a aparente segmentação do palpo labial. No entanto, cabe ressaltar que algumas espécies do gênero, descritas até o final da década de 1990, apresentam descrições incompletas. Desta forma, a fim de confirmar a identificação, seria necessário consultar o material-tipo.

Material examinado (3): PT 30: (1) 24.x.2001; PT 39: (2) 21.x.2004.
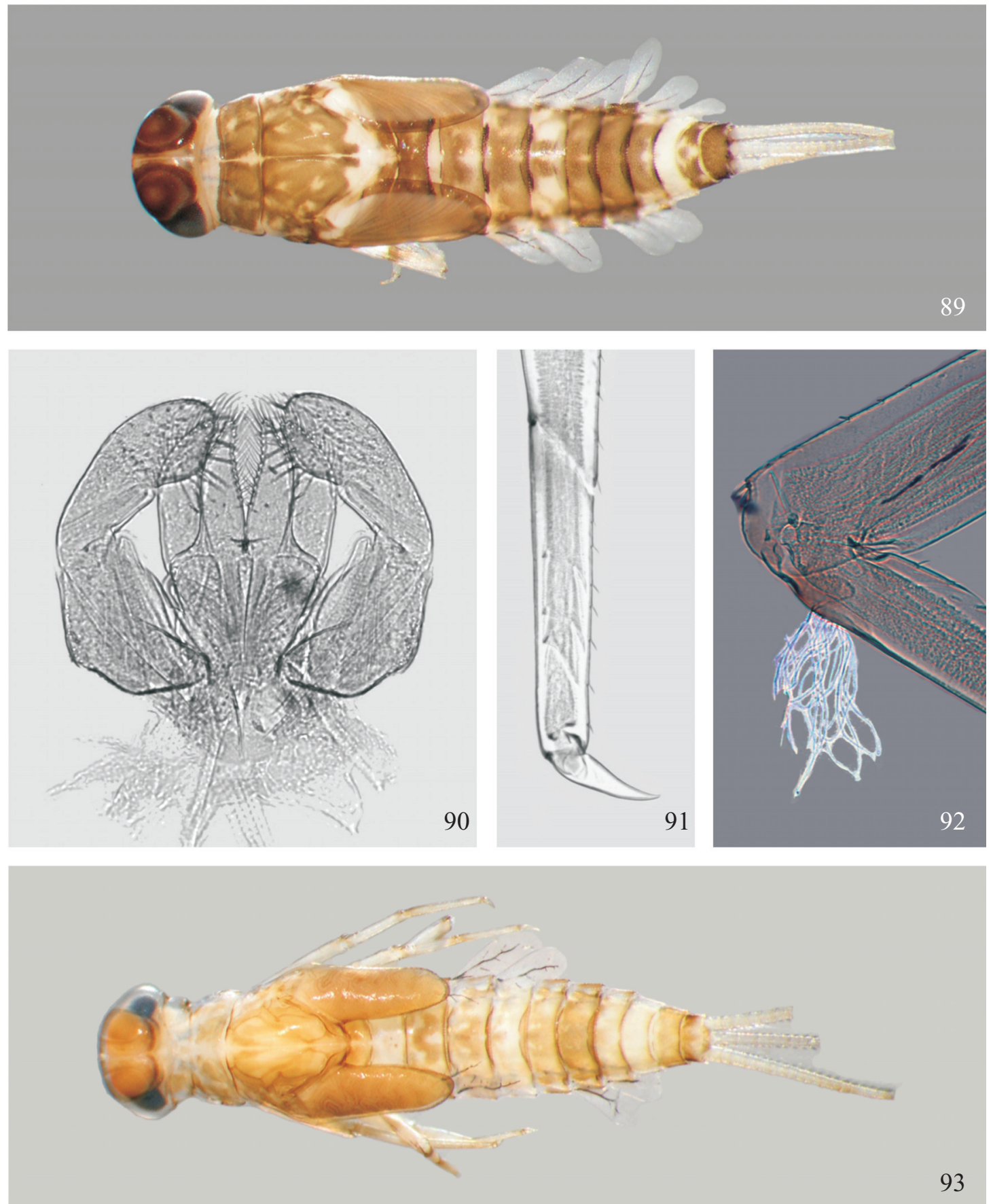

Figs. 89-93. Cloeodes barituensis Nieto \& Richard, 2008 (89 e 90). 89. Vista dorsal (ơ). 90. Lábio. Cloeodes cf. hydation McCafferty \& Lugo-Ortiz, 1995 (91-93). 91. Porção apical da perna. 92. Detalhe da base da tíbia. 93. Vista dorsal (Ơ). 


\section{Cryptonympha copiosa Lugo-Ortiz \& McCafferty, 1998}

(Figs. 94-99)

Comentários: Amplamente distribuída nas regiões Sul e Norte, incluindo os estados do Acre, Amazonas e Pará (Salles et al. 2004b), foi uma das espécies mais abundantes no presente trabalho, tendo ocorrido em $50 \%$ dos cursos d'água analisados.
Material examinado (556): PT 01: (2) 24.x.2001, (40) 03.xi.2006; PT 02: (9) 03.xi.2006; PT 04: (12) 04.xi.2006; PT 05: (2) 22.iii.2001, (1) 04.xi.2006, (23) 04.ii.2007; PT 07: (28) 06.xi.2006; PT 08: (11) 07.xi.2006; PT 09: (3) 07.xi.2006; PT 13: (13) 09.xi.2006; PT 14: (21) 09.xi.2006; PT 15: (6) 10.xi.2006; PT 16: (15) 10.xi.2006, (7) 03.ii.2007; PT 18: (66) 13.xi.2006; PT 19: (85) 14.xi.2006; PT 20: (7) 14.xi.2006; PT 21: (80) 14.xi.2006; PT 22: (9) 15.xi.2006; PT 23: (18) 15.xi.2006; PT 24: (23) 15.xi.2006; PT 25: (1) 16.xi.2006; PT 29: (1) 17.xi.2006; PT 30: (19) 03.ii.2007; PT 32: (1) 20.iii.2001; PT 33: (1) 22.x.2004; PT 42: (1) 18.x.2004, (2) 21.xi.2006, (1) 12.ii.2007; PT 45: (1) 22.xi.2006; PT 51: (13) 25.xi.2006; PT 52: (2) 25.xi.2006; PT 55: (14) 26.xi.2006; PT 56: (5) 27.xi.2006; PT 57: (3) 28.xi.2006; PT 62: (1) 30.xi.2006; PT 63: (4) 30.xi.2006; PT 65: (5) 01.xii.2006.
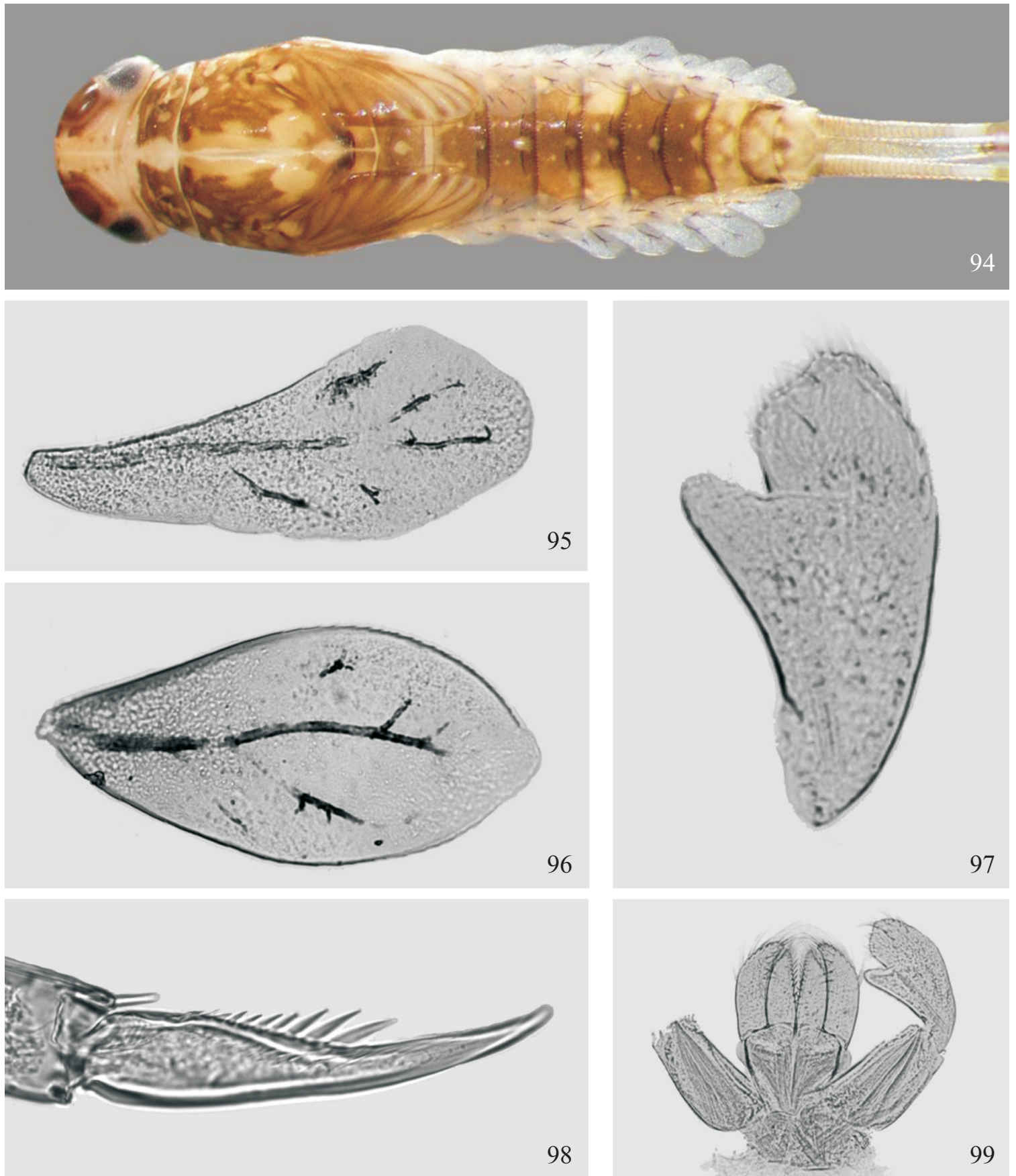

Figs. 94-99. Cryptonympha copiosa Lugo-Ortiz \& McCafferty, 1998. 94. Vista dorsal (Ơ). 95. Brânquia I. 96. Brânquia IV. 97. Palpo labial. 98. Garra tarsal. 99. Lábio. 


\section{Cryptonympha sp.}

(Figs. 100-104)

Comentários: Trata-se de uma nova espécie de Cryptonympha Lugo-Ortiz \& McCafferty, 1998, que será descrita em breve junto com outras espécies do gênero. Até o momento só é conhecida de Roraima.
Guajirolus rondoni Salles, 2007

(Figs. 105-111)

Comentários: Guajirolus Flowers, 1985 foi reportado recentemente para o Brasil, sendo registrado aqui pela primeira vez para o estado de Roraima. A espécie G. rondoni foi descrita para Rondônia, sendo este o primeiro registro fora da localidade-tipo (Salles 2007).

Material examinado: PT 59: (1) 29.xi.2006.
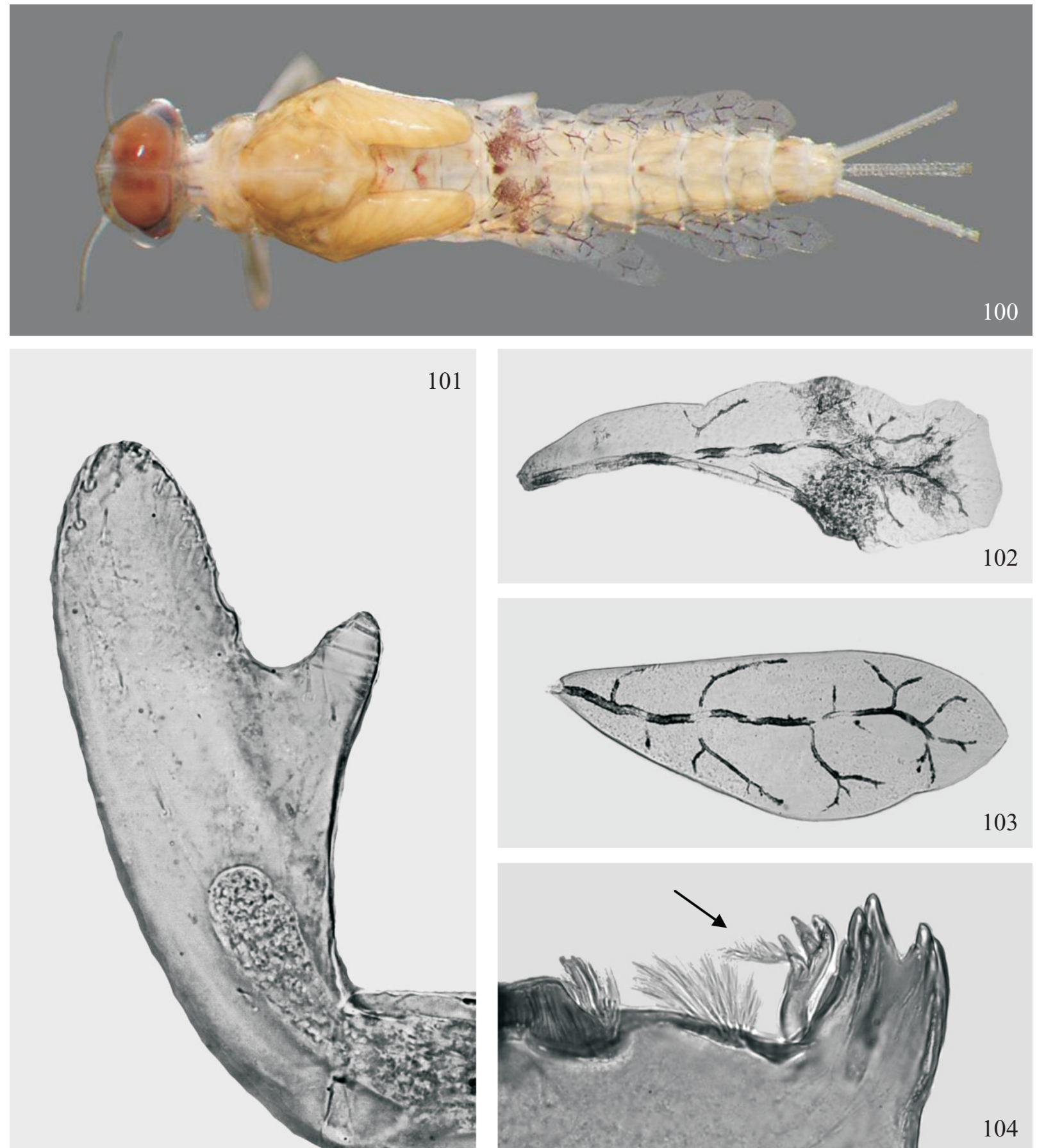

102
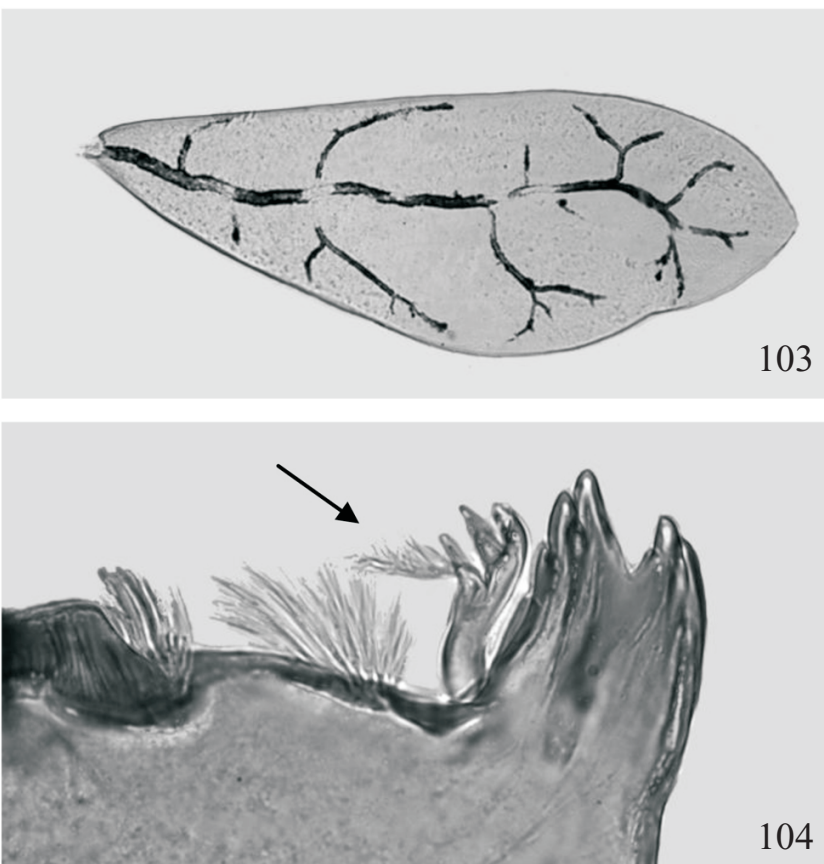

104

Figs. 100-104. Cryptonympha sp. 100. Vista dorsal (ơ). 101. Palpo labial. 102. Brânquia I. 103. Brânquia IV. 104. Detalhe da mandíbula direita. 

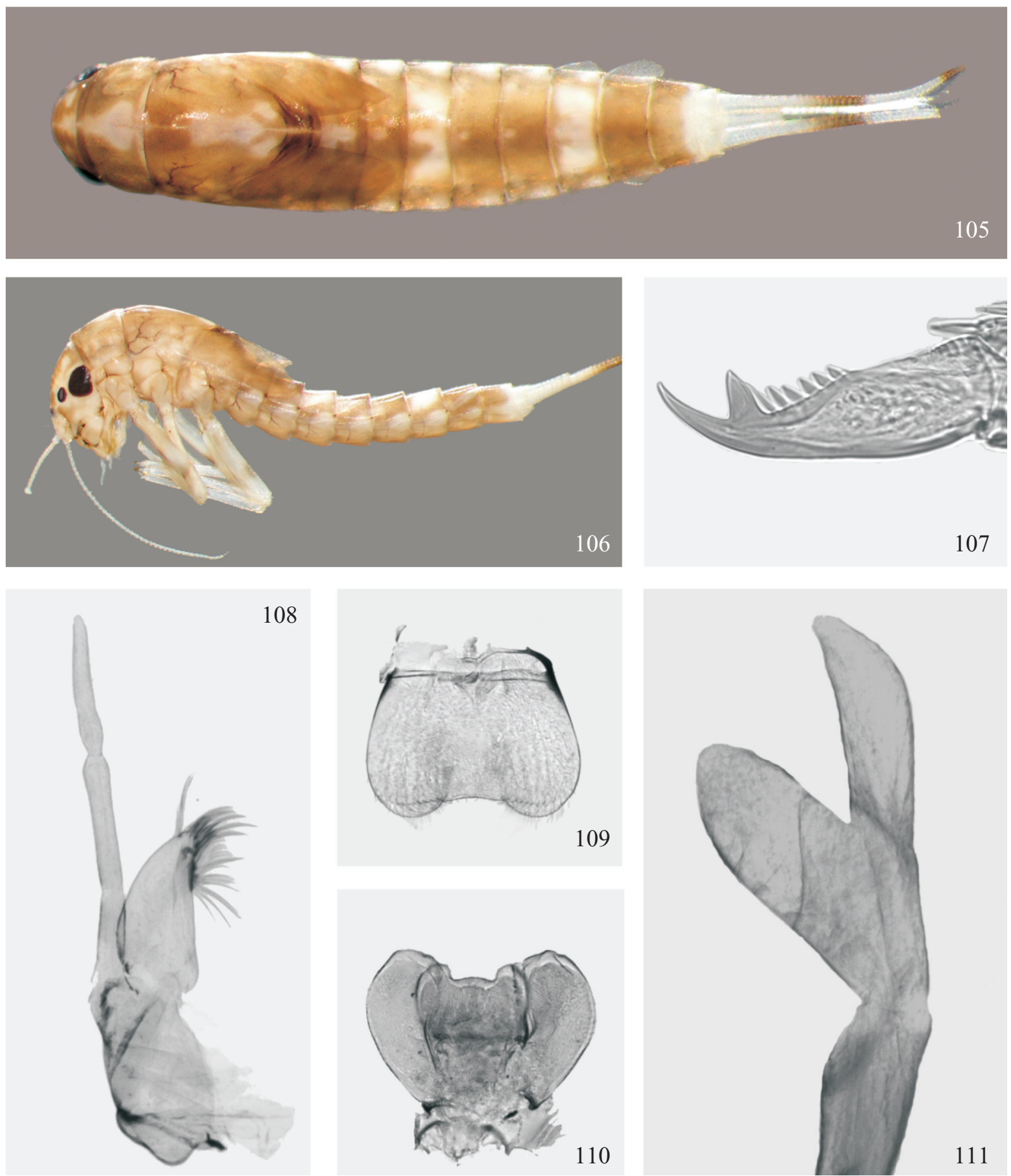

Figs. 105-111. Guajirolus rondoni Salles, 2007. 105. Vista dorsal (Q). 106. Vista lateral. 107. Garra tarsal. 108. Maxila. 109. Labro. 110. Hipofaringe. 111. Palpo labial.

\section{Harpagobaetis gulosus Mol, 1986}

(Figs. 112-118)

Comentários: Gênero monotípico descrito para o Suriname, foi previamente relatado no Brasil para os estados de Goiás e Mato Grosso (Salles \& Lugo-Ortiz 2002b; Salles et al. 2004a), e mais recentemente, a partir da descri- ção dos adultos, foi relatado pela primeira vez para Roraima e Região Norte (Falcão et al. 2010). É importante ressaltar que a espécie é relativamente comum para o estado, ocorrendo principalmente na área de savana.

Material examinado (214): PT 04: (7) 04.xi.2006; PT 05: (1) 22.iii.2001, (6) 05.xi.2006, (12) 04.ii.2007, (1) 07.ii.2007; PT 07: (7) 05.xi.2006; PT 09: (2) 07.xi.2006; PT 13: (11) 09.xi.2006; PT 14: (4) 09.xi.2006; PT 15: (6) 
10.xi.2006; PT 16: (9) 10.xi.2006; PT 18: (1) 13.xi.2006; PT 21: (1) 14.xi.2006; PT 22: (3) 15.xi.2006; PT 24: (4) 15.xi.2006; PT 26: (1) 16.xi.2006, (12) 06.ii.2007; PT 30: (14) 03.ii.2007, (2) 08.ii.2007; PT 31:
(1) 21.x.2004; PT 35: (32) 24.x.2004, (10) 05.ii.2007; PT 37: (1) 23.iii.2002;

PT 42: (3) 18.x.2004, (22) 09.ii.2007; PT 56: (4) 27.xi.2006, (5) 13.ii.2007;

PT 63: (1) 11.ii.2007; PT 65: (19) 01.xii.2006; PT 66: (12) 14.ii.2007.
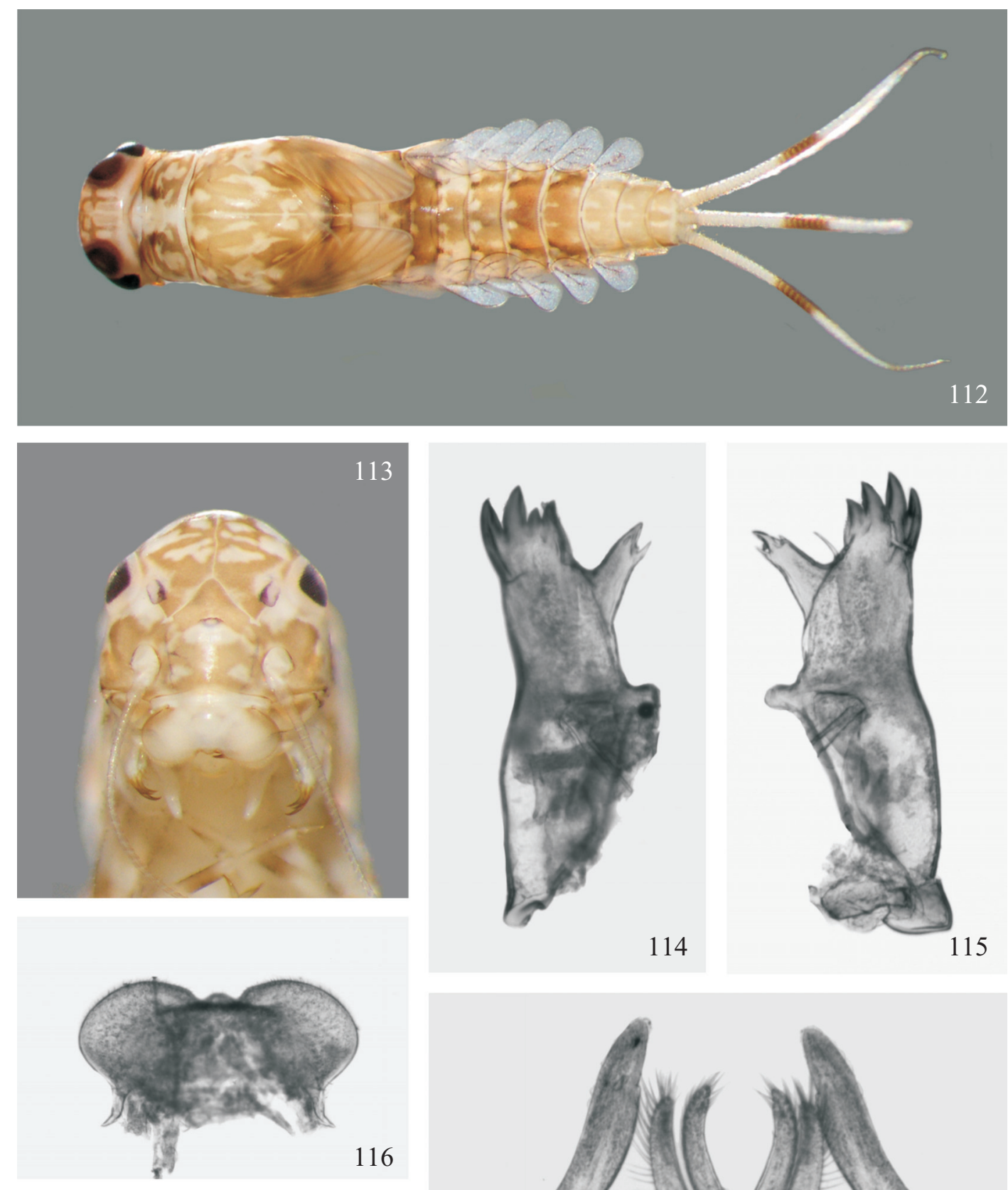

114
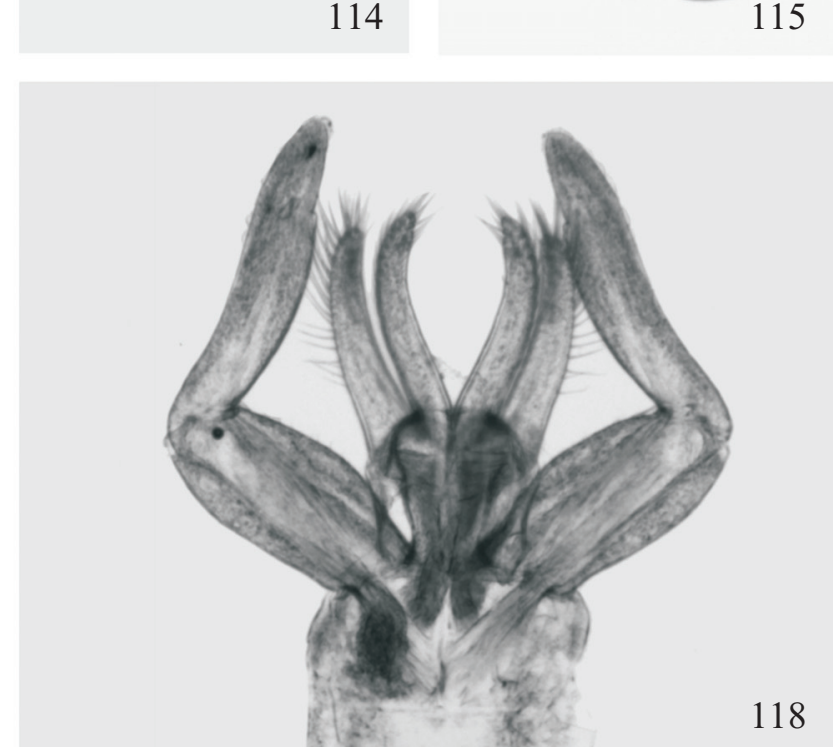

Figs. 112-118. Harpagobaetis gulosus Mol, 1986. 112. Vista dorsal (Ơ). 113. Vista dorsal da cabeça (q). 114. Mandíbula esquerda. 115. Mandíbula direita. 116. Labro. 117. Hipofaringe. 118. Lábio. 


\section{Paracloeodes atroari Nieto \& Salles, 2006}

(Figs. 119-120)

Comentários: Descrita recentemente para o estado do Amazonas (Nieto \& Salles 2006), é reportada pela primeira vez fora da sua localidade-tipo, expandindo ao norte a sua distribuição.

Material examinado (12): PT 01: (1) 03.xi.2006; PT 15: (1) 10.xi.2006; PT 28: (7) 17.xi.2006; PT 43: (1) 21.xi.2006; PT 54: (1) 26.xi.2006.
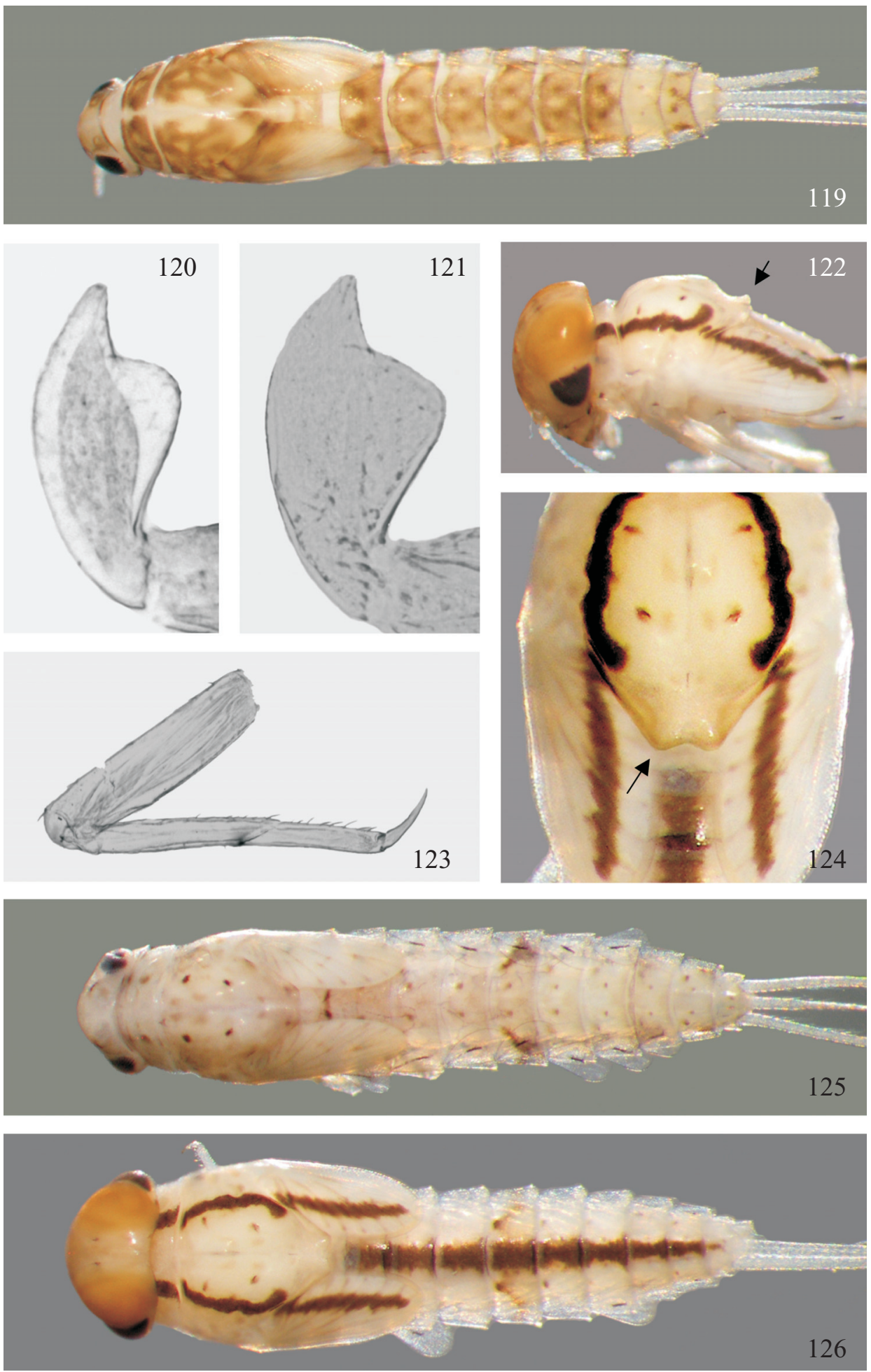

Figs. 119-126. Paracloeodes atroari Nieto \& Salles, 2006 (119-120). 119. Vista dorsal (Q). 120. Palpo maxilar. Paracloeodes binodulus Lugo-Ortiz \& McCafferty, 1996 (121-126). 121. Palpo labial. 122. Perna. 123. Vista lateral do tórax. 124. Vista dorsal do tórax. 125 e 126 . Vista dorsal (125 - @; 126 - O'). 


\section{Paracloeodes binodulus Lugo-Ortiz \& McCafferty, 1996}

(Figs. 121-126)

Comentários: Descrita para o Pará, e registrada posteriormente para o Mato Grosso (Salles et al. 2004a) e Amazonas (Nieto \& Salles 2006). O novo registro para Roraima estende ao norte a sua distribuição previamente conhecida.

Material examinado (75): PT 01: (2) 03.xi.2006; PT 05: (8) 04.xi.2006, (6) 04.ii.1007; PT 07: (1) 06.xi.2006; PT 09: (1) 07.xi.2006; PT 13: (1) 09.xi.2006; PT 15: (2) 10.xi.2006; PT 16: (1) 03.ii.2007; PT 22: (1) 15.xi.2006; PT 23: (2) 15.xi.2006; PT 43: (1) 21.xi.2006; PT 47: (1) 24.xi.2006; PT 48: (4) 24.xi.2006; PT 49: (10) 24.xi.2006; PT 51: (3) 25.xi.2006; PT 54: (7) 26.xi.2006; PT 59: (1) 29.xi.2006; PT 60: (4) 29.xi.2006; PT 61: (4) 29.xi.2006; PT 62: (13) 30.xi.2006; PT 66: (2) 14.ii.2007.

\section{Paracloeodes cf. leptobranchus Lugo-Ortiz \& McCafferty, 1996}

(Figs. 127-128)

Comentários: Paracloeodes leptobranchus foi descrita para o Brasil e Paraguai, juntamente com a espécie P. eurybranchus Lugo-Ortiz \& McCafferty, 1996 (Lugo-Ortiz \& McCafferty 1996). No entanto, suas descrições são incompletas, com poucas diferenças consistentes entre elas, já tendo sido sugerido uma possível sinonímia (Nieto \& Salles 2006). Os indivíduos coletados em Roraima, embora similares a $P$. eurybranchus, são menores e apresentam brânquias mais agudas no ápice, características que os aproximam mais a P. leptobranchus. Será necessário examinar o material-tipo para solucionar as dúvidas existentes quanto à identificação dessas espécies.

Material examinado (11): PT 32: (1) 20.iii.2001, (1) 22.x.2004; PT 33: (2) 22.x.2004; PT 39: (1) 21.x.2004; PT 48: (1) 24.xi.2006; PT 57: (1) 12.ii.2007; PT 59: (1) 29.xi.2006, (1) 14.ii.2007; PT 61: (2) 29.xi.2006.

\section{Paracloeodes pacawara Nieto \& Salles, 2006}

(Figs. 129-130)

Comentários: Descrita recentemente para Bolívia (Nieto \& Salles 2006). Este novo registro para o estado de Roraima representa também o primeiro registro da espécie para o Brasil e estende consideravelmente ao norte a sua distribuição.

Material examinado (2): PT 10: (2) 08.xi.2006.

\section{Paracloeodes waimiri Nieto \& Salles, 2006}

(Figs. 131-132)

Comentários: Descrita para o estado do Amazonas (Nieto \& Salles 2006), é registrada aqui pela primeira vez fora da sua localidade-tipo, estendendo ao norte sua distribuição.

Material examinado (52): PT 22: (3) 15.xi.2006; PT 26: (4) 16.xi.2006; PT 29: (1) 17.xi.2006; PT 39: (1) 21.x.2004; PT 43: (3) 21.xi.2006; PT
51: (1) 25.xi.2006; PT 57: (1) 12.ii.2007; PT 59: (5) 29.xi.2006; PT 60: (10) 29.xi.2006; PT 61: (19) 29.xi.2006; PT 64: (1) 30.xi.2006; PT 66: (3) 14.ii.2007.

\section{Rivudiva trichobasis Lugo-Ortiz \& McCafferty, 1998}

(Figs. 133-138)

Comentários: Rivudiva Lugo-Ortiz \& McCafferty, 1998 foi descrito para abrigar duas espécies do Brasil, ambas descritas a partir de ninfas (Lugo-Ortiz \& McCafferty 1998), tendo sido relatado posteriormente para a Guiana Francesa (Orth et al. 2000). Recentemente, a partir da descrição dos adultos de $R$. minantenna Lugo-Ortiz \& McCafferty, 1998, duas espécies foram transferidas para o gênero (Salles \& Cavalcante do Nascimento 2009). Atualmente, encontra-se registrado no Brasil para os estados do Espírito Santo, Rio de Janeiro, Santa Catarina e Rio Grande do Sul, sendo que a espécie $R$. trichobasis permanece até o presente relatada somente para o Rio Grande do Sul (Salles et al. 2004b). Aqui, a espécie é registrada para o estado de Roraima, constituindo também o primeiro registro da espécie e do gênero para a Região Norte. Este registro estende a distribuição da espécie ao norte da América do Sul, demonstrando a necessidade de maiores esforços amostrais da família no continente e principalmente no Brasil.

Material examinado (3): PT 49: (1) 24.xi.2006; PT 57: (1) 28.xi.2006; PT 58: (1) 28.xi.2006.

Spiritiops silvudus Lugo-Ortiz \& McCafferty, 1998 (Figs. 139-145)

Comentários: Até o presente, é a única espécie conhecida do gênero e ocorre nos estados do Amazonas, Mato Grosso, Pará (Salles et al. 2004b) e Bahia (Lima et al. 2010). Apesar de o gênero ter sido reportado para a Guiana Francesa (Orth et al. 2000) e para o Suriname (Salles \& Nieto 2008), estes foram feitos através de espécies não identificadas. Assim, o registro da espécie para o estado de Roraima estende ao norte a sua distribuição previamente conhecida.

Material examinado (73): PT 17: (6) 11.xi.2006; PT 25: (1) 16.xi.2006; PT 26: (11) 16.xi.2006; PT 27: (10) 16.xi.2006; PT 31: (1) 19.iii.2001; PT 32: (2) 13.xii.2000, (1) 22.x.2004; PT 33: (25) 22.x.2004; PT 35: (1) 24.x.2004, (2) 05.ii.2007; PT 37: (1) 03.x.2002; PT 40: (1) 22.iii.2002; PT 42: (1) 18.x.2004; PT 65: (10) 01.xii.2006.

\section{Waltzoyphius roberti Thomas \& Péru, 2002}

(Figs. 146-151)

Comentários: Waltzoyphius McCafferty \& Lugo-Ortiz, 1998 apresenta atualmente duas espécies, $W$. fasciatus McCafferty \& Lugo-Ortiz, 1998 amplamente distribuída no Brasil (Salles et al. 2004b; Lima et al. 2010) e W. roberti, descrita com base em exemplares da Guiana Francesa (Thomas \& Peru 2003). O registro de W. roberti para o estado de Roraima consiste no primeiro registro da espécie para o Brasil. 

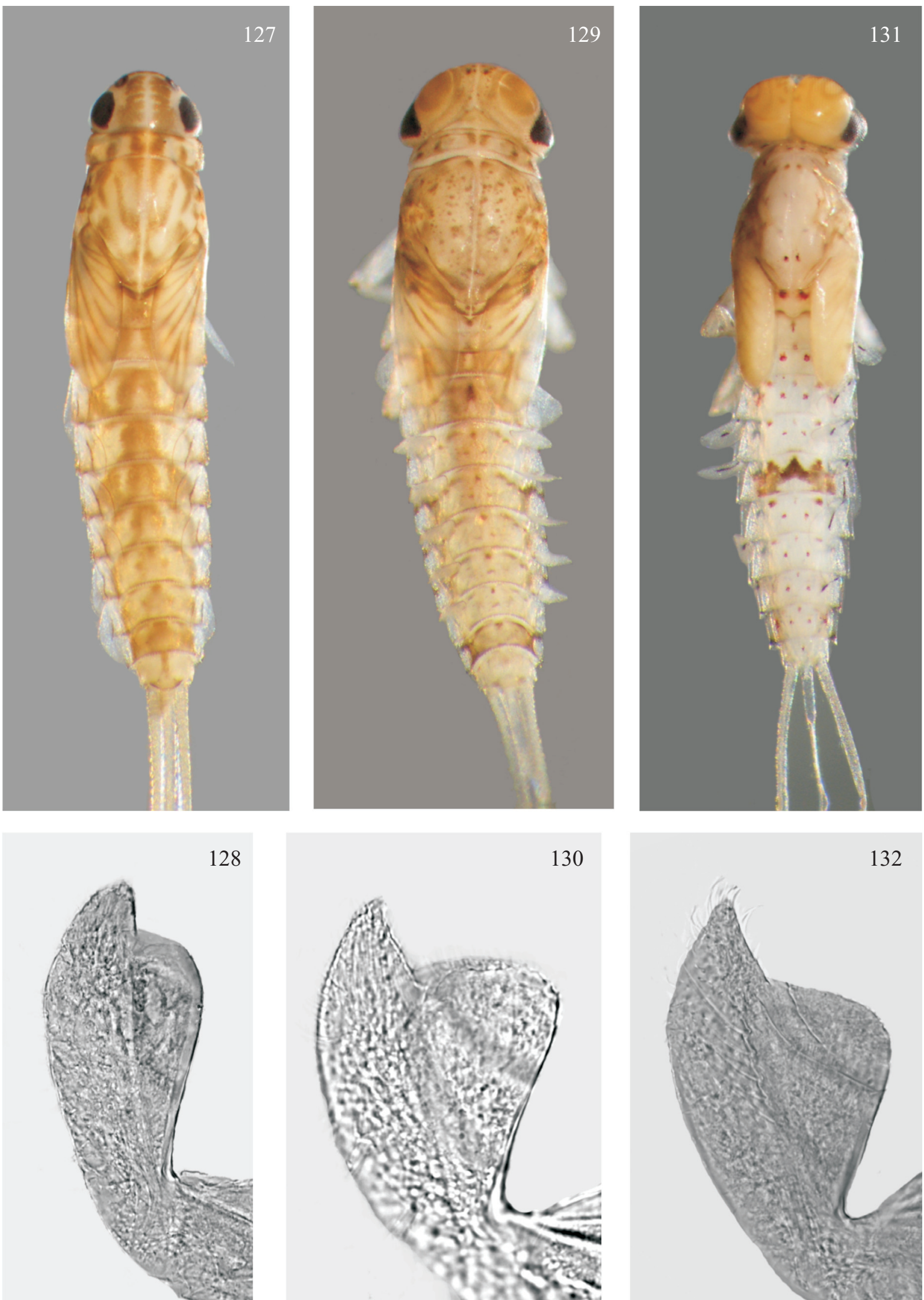

Figs. 127-132. Paracloeodes cf. leptobranchus Lugo-Ortiz \& McCafferty, 1996 (127-128). 127. Vista dorsal (O). 128. Palpo labial. Paracloeodes pacawara Nieto \& Salles, 2006 (129-130). 129. Vista dorsal (O'). 130. Palpo labial. Paracloeodes waimiri Nieto \& Salles, 2006 (131-132). 131. Vista dorsal (O'). 132. Palpo labial. 

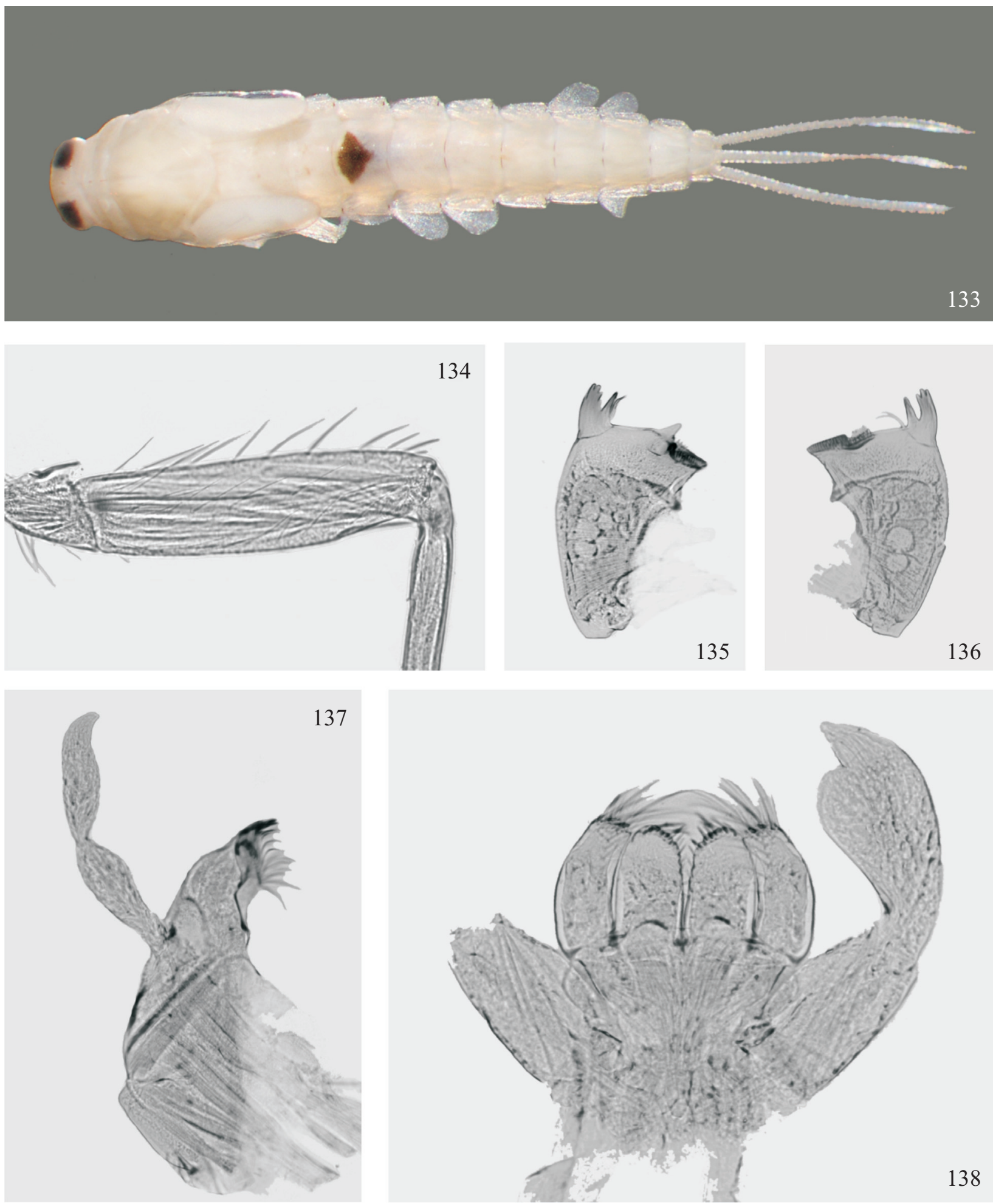

138

Figs. 133-138. Rivudiva trichobasis Lugo-Ortiz \& McCafferty, 1998. 133. Vista dorsal (Q). 134. Detalhe do fêmur. 135. Mandíbula esquerda. 136. Mandíbula direita. 137. Maxila. 138. Lábio.

Material examinado (156): PT 01: (1) 03.xi.2006; PT 03: (5) 04.xi.2006; PT 04: (3) 04.xi.2006; PT 07: (15) 06.xi.2006; PT 12: (1) 09.xi.2006; PT 13: (2) 09.xi.2006; PT 14: (1) 09.xi.2006; PT 16: (1) 10.xi.2006, (1) 03.ii.2007; PT 18: (4) 13.xi.2006; PT 20: (1) 14.xi.2006; PT 23: (9) 15.xi.2006; PT 25: (8) 16.xi.2006; PT 26: (1) 16.xi.2006; PT
46: (11) 23.xi.2006; PT 47: (2) 24.xi.2006; PT 48: (12) 24.xi.2006; PT 49: (1) 24.xi.2006; PT 50: (1) 25.xi.2006; PT 51: (15) 25.xi.2006; PT 52: (5) 25.xi.2006; PT 54: (4) 26.xi.2006; PT 57: (8) 28.xi.2006; PT 58: (4) 28.xi.2006; PT 59: (1) 29.xi.2006; PT 60: (2) 29.xi.2006; PT 61: (1) 29.xi.2006; PT 62: (35) 30.xi.2006; PT 64: (1) 30.xi.2006. 

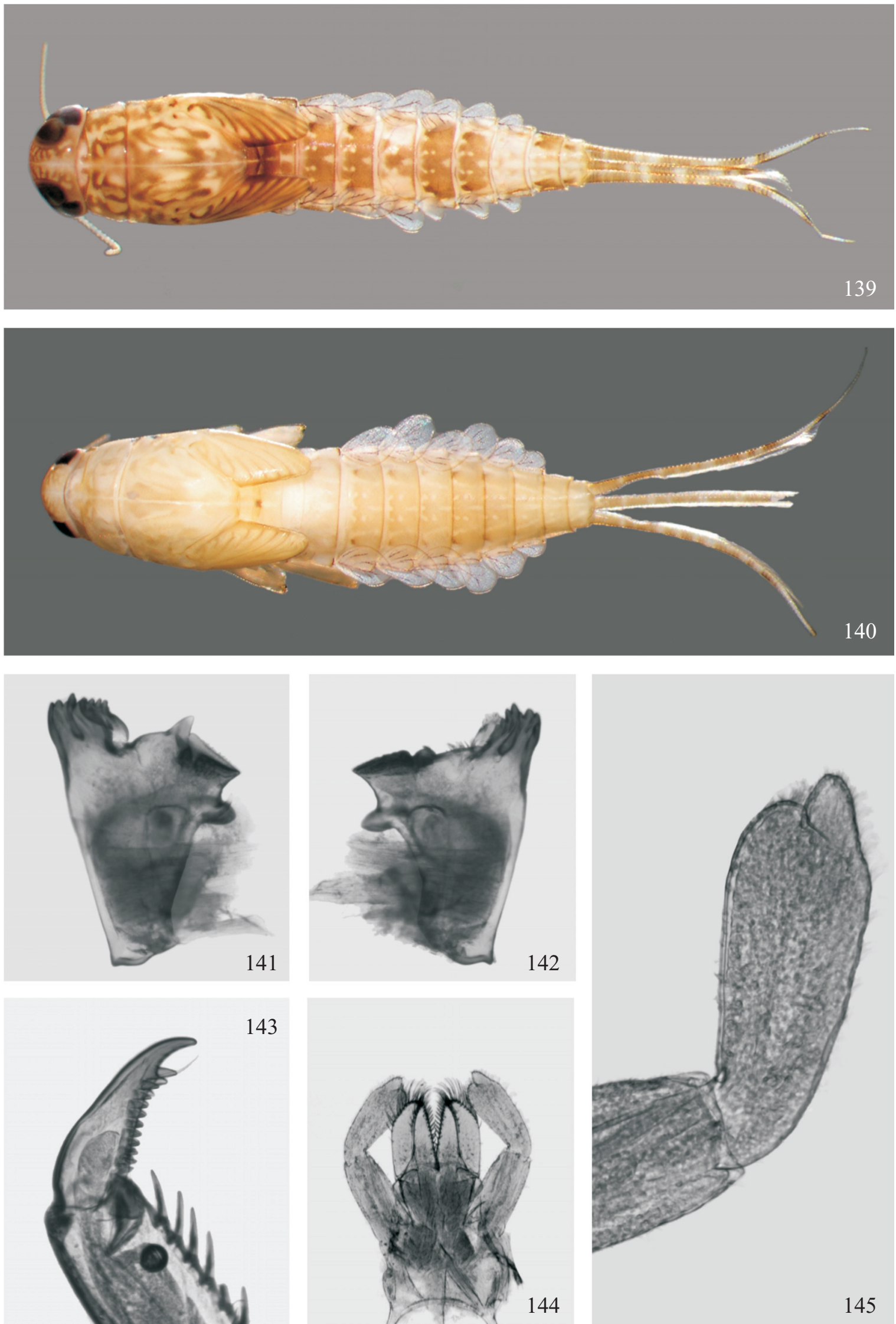

Figs. 139-145. Spiritiops silvidus Lugo-Ortiz \& McCafferty, 1998. 139 e 140. Vista dorsal (139 - ơ; 140 - @). 141. Mandíbula esquerda. 142. Mandíbula direita. 143. Garra tarsal. 144. Lábio. 145. Palpo labial. 

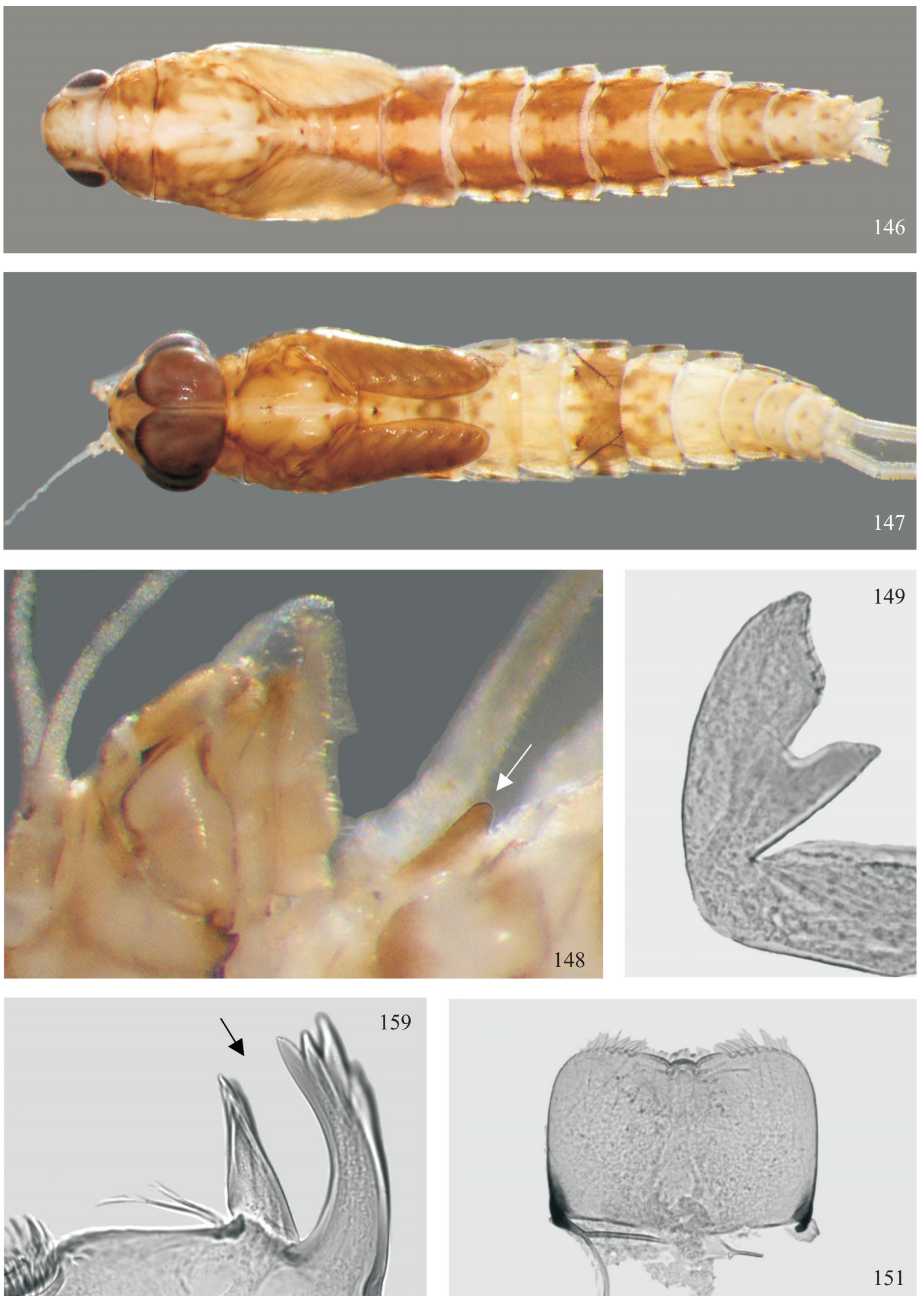

Figs. 146-151. Waltzoyphius roberti Thomas \& Peru, 2002. 146 e 147. Vista dorsal (146- @; 147 - O'). 148. Projeção metatorácica. 149. Palpo labial. 150. Detalhe da mandíbula direita. 151. Labro. 


\section{Zelusia principalis Lugo-Ortiz \& McCafferty, 1998} (Figs. 152-157)

Comentários: O gênero monotípico Zelusia Lugo-Ortiz \& McCafferty, 1998 foi criado para abrigar a espécie $Z$. principalis (Lugo-Ortiz \& McCafferty 1998), atualmente registrada somente para o Brasil, para as Regiões CentroOeste, Sudeste, Norte (Amazonas e Pará) (Salles et al. 2004b) e Nordeste (Lima et al. 2010). O novo registro da espécie e gênero para o estado de Roraima amplia discretamente a sua distribuição ao norte.

Material examinado (80): PT 07: (3) 06.xi.2006; PT 12: (8) 09.xi.2006; PT 16: (14 10.xi.2006, (1) 03.ii.2007; PT 17: (1) 11.xi.2006; PT 21: (1) 14.xi.2006; PT 24: (1) 15.xi.2006; PT 27: (1) 16.xi.2006; PT 30: (1) 24.x.2001; PT 31: (4) 12.xii.2000, (1) 19.iii.2001, (2) 21.x.2004; PT 43: (3) 21.xi.2006; PT 44: (2) 21.xi.2006; PT 45: (1) 22.xi.2006; PT 46: (3) 23.xi.2006; PT 48: (1) 24.xi.2006; PT 50: (1) 25.xi.2006; PT 51: (5) 25.xi.2006; PT 56: (1) 27.xi.2006; PT 57: (4) 28.xi.2006; PT 59: (7) 29.xi.2006; PT 60: (1) 29.xi.2006; PT 61: (2) 29.xi.2006; PT 62: (11) 30.xi.2006.
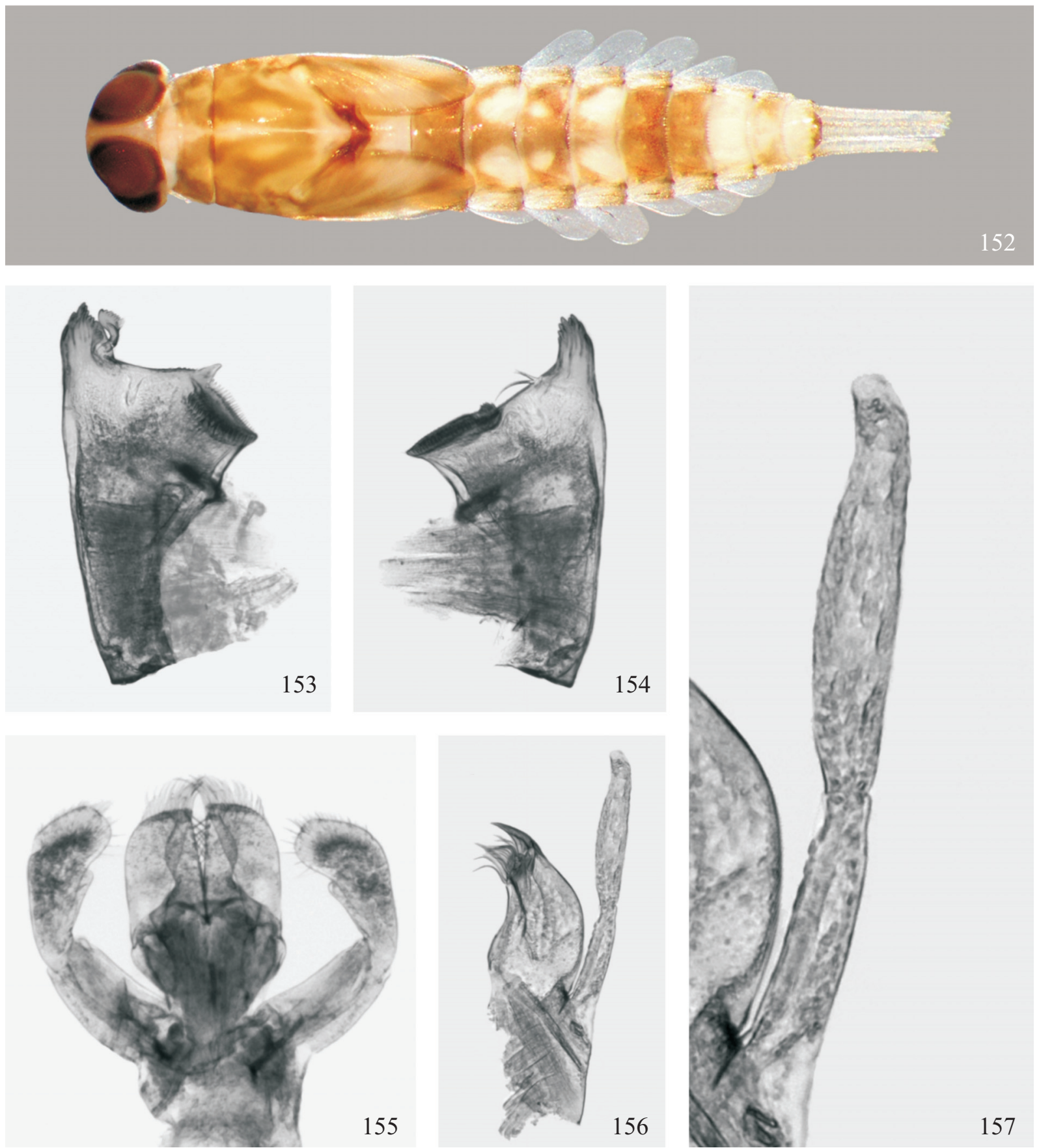

157

Figs. 152-157. Zelusia principalis Lugo-Ortiz \& McCafferty, 1998. 152. Vista dorsal (ơ). 153. Mandíbula esquerda. 154. Mandíbula direita. 155. Lábio. 156. Maxila. 157. Palpo maxilar. 


\section{Baetidae gen. nov. e sp. nov.}

(Figs. 158-163)

Comentários: Trata-se de um novo gênero e espécie de Baetidae, os quais serão descritos em breve. Até o momento só é conhecido de Roraima.

\section{Material examinado (2): PT 63: (2) 30.xi.2006.}

\section{DISCUSSÃO}

Com os novos registros, Roraima passou de um dos estados brasileiros menos estudados, a um dos estados com o maior número de táxons documentados da família Baetidae no país, com 32 espécies. O número de gêneros é o maior dentre os estados brasileiros. Dos 22 gêneros relatados para o Brasil, já incluindo o novo gênero reportado no presente trabalho, só não foram encontrados Moribaetis Waltz \& McCafferty, 1985, Tomedontus Lugo-Ortiz \& McCafferty, 1995, Tupiara Salles, Lugo-Ortiz, Da-Silva \& Francischetti, 2003 e Varipes Lugo-Ortiz \& McCafferty, 1998. No entanto, é importante ressaltar que embora o estado apresente $47 \%$ da atual fauna brasileira de Baetidae, toda a região oeste de Roraima ainda não foi amostrada.

As espécies Camelobaetidius ortizi, Cloeodes barituensis, Paracloeodes pacawara e Waltzoyphius roberti foram reportadas pela primeira vez para o Brasil, elevando o número de espécies conhecidas da família para 75. A Região Norte, por sua vez, tida como uma das mais conhecidas com relação à fauna de Ephemeroptera do país (Salles et al. 2004b), teve 14 novos registros de espécies. Além disso, os gêneros Baetodes Needham \& Murphy, 1924, Cloeodes Traver, 1938 e Rivudiva Lugo-Ortiz \& McCafferty, 1998 não haviam sido registrados para a essa região anteriormente (Salles et al. 2004b; Pes et al. 2007; Salles 2007). Ressaltamos ainda o fato de terem sido encontrados, no estado de Roraima, um gênero e duas novas espécies de Baetidae. Apesar de muitos estudos serem desenvolvidos no país acerca da taxonomia do grupo, é extremamente rara a descoberta de um novo gênero. $O$ elevado número de novas ocorrências reafirma o baixo conhecimento sobre a distribuição da família no Brasil, que apresenta registros apenas pontuais. É importante observar que, apesar do elevado conhecimento a respeito da fauna de Baetidae na Região Norte, a informação disponível sobre os estados do Acre, Amapá, Rondônia e Tocantins permanece praticamente inexistente. Desta forma, a ampliação de inventários nessas áreas do país é essencial para o conhecimento dos Baetidae da RegiãoNorte e, conseqüentemente, do Brasil.

\section{Chave para identificação das ninfas das espécies de} Baetidae para Roraima

1. Garras tarsais espatuladas (ex. Figs. 46 e 50) Camelobaetidius -2

1'. Garras tarsais afiladas apicalmente (ex. Figs. 20, 31 e 39)
2. Filamento mediano extremamente reduzido, de tamanho aproximado ao último segmento abdominal (Fig. 49) ....

C. billi (Figs. 48-55)

2'. Filamento mediano de tamanho aproximado ao dos cer$\cos$ (ex. Fig. 56) 3

3. Teca alar posterior ausente ........ C. matilei (Figs. 66-70)

3'. Teca alar posterior presente

4

4. Palpo maxilar bífido (Fig. 64) ..... C. janae (Figs. 61-65) 4'. Palpo maxilar simples (ex. Figs. 47 e 60) ................... 5

5. Brânquia na base da coxa anterior presente (Fig. 44) ..... C. anubis (Figs. 43-47)

5'. Brânquia na base da coxa anterior ausente 6

6. Segundo artículo do palpo labial com projeção disto-mediana triangular, (Fig. 59); labro estreitado anteriormente (Fig. 58) C. cayumba (Figs. 56-60)

6'. Segundo artículo do palpo labial com projeção disto-mediana arredondada, (Fig. 75); labro não estreitado anteriormente (Fig. 73) C. ortizi (Figs. 71-75)

7. Filamento mediano extremamente reduzido, de tamanho aproximado ao do último segmento abdominal; brânquias presentes nos segmentos I a $\mathrm{V}$

Baetodes cf. proiectus (Figs. 30-36)

7'. Filamento mediano de tamanho aproximado ao dos cercos; brânquias presentes nos segmentos I a VII ou II a VII ..... 8

8. Brânquias em geral apresentando dobras (aparentando ter mais de uma lamela) (Fig. 40); garras tarsais anteriores com duas fileiras de dentículos longos (Fig. 39)

Callibaetis (Figs. 37-42)

8'. Brânquias com uma única lamela, sem dobras; garras tarsais anteriores lisas ou com dentículos (ex. Figs. 20, 79 e 98), mas nunca com duas fileiras de dentículos longos ......... 9

9. Garras tarsais lisas (ex. Fig. 20) ................................. 10

9'. Garras tarsais com dentículos (ex. Fig. 98) ................ 13

10. Garras tarsais curtas, no máximo 0,5 vezes o comprimento do tarso (ex. Figs. 87 e 91); base das tíbias com arco de cerdas longas e finas (Fig. 92) ..... Cloeodes -11

$10^{\prime}$. Garras tarsais longas, mais de 0,7 vezes o comprimento do tarso (Fig. 17); sem arco de cerdas na base da tíbia .. Apobaetis fiuzai (Figs. 14 e 20)

11. Tecas alares posteriores presentes C. cf. hydation (Figs. 91-93)

11'. Tecas alares posteriores ausentes 12

12. Terceiro artículo do palpo labial robusto e de ápice truncado (Fig. 86); padrão de coloração como na Figura 83 ... C. auwe (Figs. 83-88)

12'. Terceiro artículo do palpo labial arredondado (Fig. 90); padrão de coloração não como acima

C. barituensis (Figs. 89-90)

13. Garras tarsais com os 3 ou 4 últimos dentículos maiores que os demais (Fig. 162); glossa com cerdas pectinadas (Fig. 159)

Baetidae gen. e sp. (Figs. 158-163) 

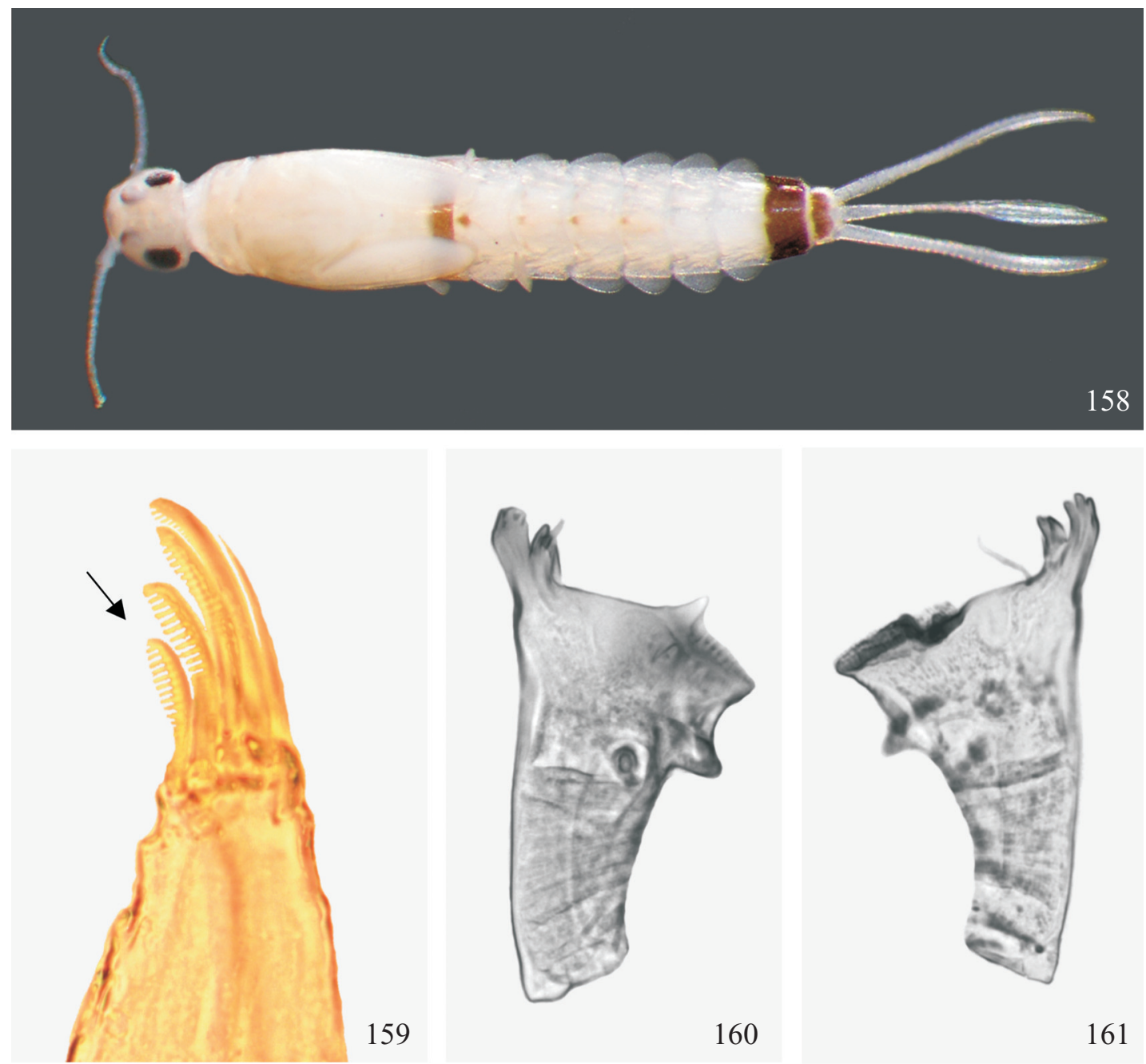

159

160

161

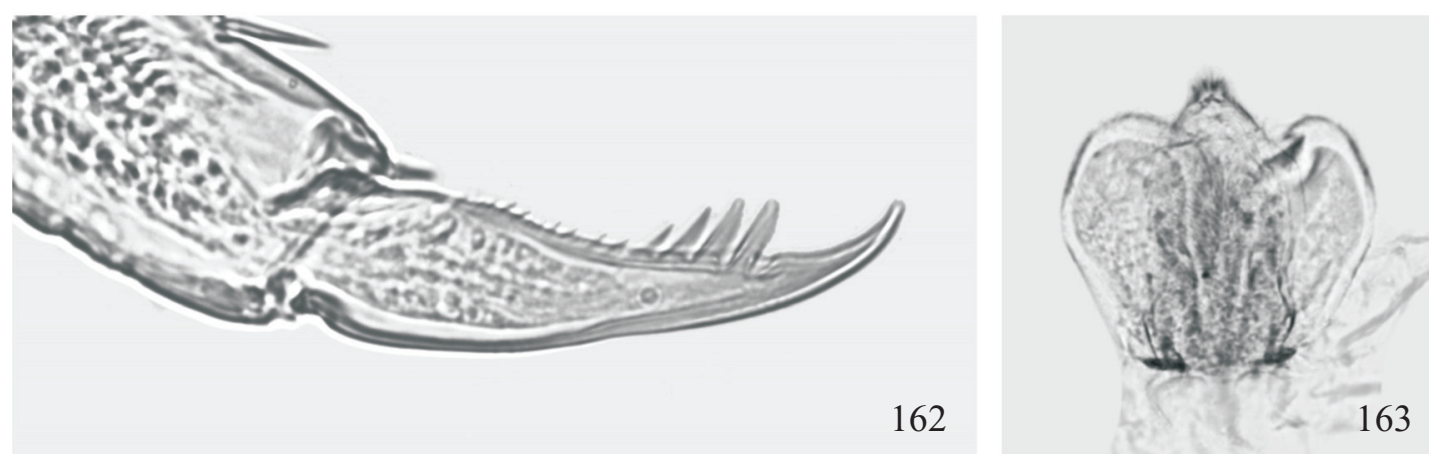

Figs. 158-163. Baetidae gen. sp. 158. Vista dorsal (o). 159. Detalhe da glossa. 160. Mandíbula esquerda. 161. Mandíbula direita. 162. Garra tarsal. 163. Hipofaringe.

13. Garras tarsais não como acima; glossa nunca com cerdas pectinadas 14

14. Garras tarsais com um dentículo pré-apical bem maior que os demais (Figs. 79 e 107)

15

14'. Garras tarsais com dentículos aumentando gradualmente em direção ao ápice (ex. Fig. 98) 16

15. Projeção interna do segundo e do terceiro artículo do palpo labial muito longa (maior do que o comprimento do primeiro artículo) e com duas fileiras de cerdas longas (Fig. 78)

Chane baure (Figs. 76-82)

15'. Projeção interna do segundo e do terceiro artículo do palpo labial menor do que o comprimento do primeiro artículo e sem cerdas longas (Fig. 111)

Guajirolus rondoni (Figs. 105-111)

16. Garras tarsais com uma forte cerda pré-apical (Fig. 143) Spiritiops silvudus (Figs. 139-145) 
16'. Garras tarsais desprovidas de cerda pré-apical ........ 17

17. Fêmur com muitas cerdas longas nas margens (Fig. 134) Rivudiva trichobasis (Figs. 133-138)

17'. Fêmur sem esse tipo de cerdas 18

18. Região molar da mandíbula modificada (projetada e pontiaguda) (Figs. 114 e 115); labro muito alargado (cerca de duas vezes o seu comprimento) (Fig. 116)....

Harpagobaetis gulosus (Figs. 112-118)

18'. Região molar da mandíbula não modificada (ex. Figs. 12 e 13); labro nunca tão alargado 19

19. Mandídulas com incisivos totalmente fusionados (ex. Figs. 10 e 104) 20

19'. Mandíbulas com incisivos parcialmente (ex. Fig. 3) ou totalmente destacados (ex. Fig. 150) 25

20. Segundo artículo do palpo labial com forte projeção distomediana (ex. Fig. 9) 21

20'. Palpo labial sem projeção no segundo artículo (ex. Figs. 27 e 28)

21. Prosteca direita desprovida de cerdas (Fig. 10); brânquias nos segmentos II a VIIAmericabaetis alphus (Figs. 6-13)

21'. Prosteca direita com uma longa cerda pectinada (Fig. 104); brânquias nos segmentos I a VII .

Cryptonympha -22

22. Terceiro artículo do palpo labial tão largo quanto longo (Fig. 97); brânquia I sem manchas (Fig. 95)

C. copiosa (Figs. 94-99)

22 '. Terceiro artículo do palpo labial alongado (1,5 vezes a sua largura) (Fig. 101); brânquia I geralmente com manchas (Fig. 102) ......... Cryptonympha sp. (Figs. 100-104)

23. Tecas alares posteriores ausentes; palpo maxilar bi-segmentado (Fig. 157) . Zelusia principalis (Figs. 152-157)

23'. Tecas alares posteriores presentes; palpo maxilar tri-segmentado (Fig. 26) Aturbina -24

24. Terceiro segmento do palpo labial quadrangular (Fig. 27) A. georgei (Figs. 21-27)

24'. Terceiro segmento do palpo labial arredondado (Fig. 28) A. nigra (Figs. 28-29)

25. Segundo artículo do palpo labial sem projeção distomediana (Fig. 4) Adebrotus amazonicus (Figs. 1-5)

25 '. Segundo artículo do palpo labial com projeção distomediana (ex. Fig. 120, 121 e 149) 26

26. Mesoesterno com projeção cônica (Fig. 148); incisivos de ambas as mandíbulas fortemente destacados (Fig. 150) Waltzoyphius roberti (Figs. 146-151)

26'. Mesoesterno sem projeção; incisivos variáveis Paracloeodes -27

27. Tórax com dois pequenos tubérculos entre as tecas alares (Figs. 123 e 124). P. binodulus (Figs. 121-126)

27'. Tórax sem tubérculos 28

28. Tecas alares posteriores ausentes 29

28 '. Tecas alares posteriores presentes
29. Mesonoto com três manchas circulares ao longo da linha média (Fig. 119); segundo artículo do palpo labial com projeção distomediana 2,3 vezes a largura do terceiro artículo (Fig. 120) P. atroari (Figs. 119 e 120)

29'. Mesonoto sem manchas circulares ao longo da linha média (Fig. 129); segundo artículo do palpo labial com forte projeção distomediana (cerca de 3,1 vezes a largura do terceiro artículo) (Fig. 130) ....

P. pacawara (Figs. 129 e 130)

30. Tergitos e esternitos abdominais com pontuações (Fig. 131); segundo artículo do palpo labial com projeção distomediana 2,25 vezes a largura do terceiro artículo (Fig. 132) P. waimiri (Figs. 131 e 132)

30'. Tergitos e esternitos abdominais sem pontuações (Fig. 127); segundo artículo do palpo labial com projeção distomediana 1,8 vezes a largura do terceiro artículo (Fig. 128) P.cf. leptobranchus (Figs. 127 e 128)

\section{AGRADECIMENTOS}

Os autores agradecem ao CNPq e ao programa PCI/INPA/ $\mathrm{MCT} / \mathrm{CNPq}$, pelas bolsas e auxílios financeiros concedidos e, ao MCT/INPA/PPI, pelo auxílio financeiro adicional. Ao núcleo de Pesquisa do INPA Roraima e o Dr. Sílvio José Reis da Silva pelo apoio na realização do trabalho de campo.

\section{REFERÊNCIAS}

Barbosa, R. I.; S. P. Nascimento; P. A. F. Amorim \& R. F. Silva. 2005. Notas sobre a composição arbóreo-arbustiva de uma fisionomia das savanas de Roraima, Amazônia Brasileira. Acta Botanica Brasílica 19: 323329.

Boldrini, R. \& F. F. Salles. 2009. A new species of two-tailed Camelobaetidius Demoulin (Ephemeroptera: Baetidae). Boletim do Museu de Biologia Mello Leitão 25: 5-12.

Cruz, P. V.; R. Boldrini \& F. F. Salles. 2011. Apobaetis Day (Ephemeroptera: Baetidae) from Northern Brazil: description of a new species and of the male imago of A. fiuzai Salles \& Lugo-Ortiz. Aquatic Insects 33: 81-90.

Dias, L. G.; F. F. Salles \& C. Molineri. 2005. Macunahyphes: a new genus for Tricorythodes australis (Ephemeroptera: Leptohyphidae). Annales de Limnologie 41: 195-201.

Domínguez, E.; C. Molineri \& R. Mariano. 2009. Revision of the South American species of Hagenulopsis Ulmer and Askola Peters (Ephemeroptera: Leptophlebiidae) with description of six new species. Zootaxa 2142: 29-44.

Domínguez, E.; C. Molineri; M. L. Pescador; M. D. Hubbard \& C. Nieto. 2006. Ephemeroptera of South America. Aquatic Biodiversity of Latin America. Vol. 2. J. Adis; J. R. Arias; G. Rueda-Delgado \& K. M. Wantzen (Eds.). Moscow and Sofia, [Pensoft], 646 p.

Dominique, Y. \& A. Thomas. 2002. Les Ephémères de la Guyane Française. 5. Description de Camelobaetidius ortizi n. sp. [Ephemeroptera: Baetidae]. Ephemera 2001 3: 27-32.

Falcão, J. N.; F. F. Salles \& N. Hamada. 2010. The adults of Harpagobaetis Mol and Tomedontus Lugo-Ortiz and McCafferty (Ephemeroptera: Baetidae) with notes on the nymphal stage. Zootaxa 2530: 39-46.

Gonçalves, I. C.; E. R. Da Silva \& J. L. Nessimian. 2010a. A new species of Thraulodes Ulmer (Ephemeroptera: Leptophlebiidae) from Southeastern Brazil. Zootaxa 2438: 61-68.

Gonçalves, I. C.; M. R. De Souza \& J. L. Nessimian. 2010b. Description of the imagos of Cloeodes jaragua Salles \& Lugo-Ortiz, 2003 (Ephemeroptera, Baetidae). Zootaxa 2487: 65-68. 
Instituto de terras e colonização de Roraima (ITERAIMA). 2005. Diagnóstico do Estado de Roraima. Boa Vista, Instituto de terras e colonização de Roraima (ITERAIMA), 115 p.

Lima, L.; F. F. Salles; E. Q. Miranda \& U. S. Pinheiro. 2010. Espécies de Baetidae (Ephemeroptera) do Sul do Estado da Bahia, Brasil, com descrição de uma nova espécie de Paracloeodes Day. Neotropical Entomology 39: 725-731.

Lugo-Ortiz, C. R. \& W. P. McCafferty. 1996. The genus Paracloeodes (Insecta, Ephemeroptera, Baetidae) and its presence in South America. Annales de Limnologie 32: 161-169.

Lugo-Ortiz, C. R. \& W. P. McCafferty. 1997. First report and new species of the genus Apobaetis (Ephemeroptera: Baetidae) from South America. Aquatic Insects 19: 243-246.

Lugo-Ortiz, C. R. \& W. P. McCafferty. 1998. Five new genera of Baetidae (Insecta: Ephemeroptera) from South America. Annales de Limnologie 34: 57-73.

Mariano, R. 2010. Two new species of Simothraulopsis Traver, 1947 (Ephemeroptera: Leptophlebiidae: Atalophlebiinae) from northeastern Brazil. Aquatic Insects 32: 129-134.

Mayo, V. N. 1973. Four new species of the genus Baetodes (Ephemeroptera: Baetidae). Pan-Pacific Entomologist 49: 308-314.

McCafferty, W. P. \& C. R. Lugo-Ortiz. 1995. Cloeodes hydation, n. sp. (Ephemeroptera: Baetidae) an extraordinary, drought tolerant mayfly from Brazil. Entomologycal News 106: 29-35.

Nieto, C. 2003. A new species of Guajirolus (Ephemeroptera: Baetidae) from Argentina and description of a new genus from Bolivia, p. 153158. In: E. Gaino (Ed.). Research Update on Ephemeroptera \& Plecoptera. Perugia, Università di Perugia. $483 \mathrm{p}$.

Nieto, C. 2004. The genus Baetodes (Ephemeroptera: Baetidae) in South America with the description of new species from Argentina, Bolivia and Peru. Studies on Neotropical Fauna and Environment 39: 63-79.

Nieto, C. 2006. New species of the genus Apobaetis Day (Ephemeroptera: Baetidae) from Bolivia and Argentina. Annales de Limnologie International Journal of Limnology 42: 189-196.

Nieto, C. \& F. F. Salles. 2006. Revision of the genus Paracloeodes (Ephemeroptera: Baetidae) in South America. Zootaxa 1301: 1-33.

Nieto, C \& B. Richard. 2008. The genus Cloeodes (Ephemeroptera: Baetidae) in Argentina with new generic synonymy and new species. Zootaxa 1727:1-21.

Orth, K.; A. G. B. Thomas; C. Dauta; V. Horeau; S. Brosse \& C. Ademmer 2000. Les Ephémères de la Guyane Francaise. 1. Premier inventaire générique, à but de biosurveillance [Ephemeroptera]. Ephemera 2: 2538 .

Pes, A. M. O.; L. V. P. Domingos; F. F. Salles; J. O. da Silva \& N. Hamada. 2007. Insetos aquáticos: Simuliidae e outros, p. 45-55. In: L. Rapp Py-Daniel; C. P. Deus; A. L. Henriques; D. M. Pimpão \& O. M. Ribeiro (orgs.). Biodiversidade do Médio Madeira: Bases científicas para propostas de conservação. Manaus, INPA, 244 p.

Salles, F. F. 2006. A ordem Ephemeroptera no Brasil (Insecta): taxonomia e diversidade. Tese de doutorado. Viçosa, Universidade Federal de Viçosa, $300 \mathrm{p}$.

Salles, F. F. 2007. The presence of Chane Nieto and Guajirolus Flowers (Ephemeroptera: Baetidae) in Brazil, with the description of a new species. Revista Brasileira de Entomologia 51: 404-409.

Salles, F. F. 2010. Taxonomy of the genus Adebrotus Lugo-Ortiz \& McCafferty (Ephemeroptera: Baetidae). Annales de Limnologie 46: 207-215.
Salles, F. F. \& C. Molineri. 2006. Amanahyphes saguassu, a new genus and species of Leptohyphidae (Ephemeroptera: Ephemerelloidea) from northern Brazil. Aquatic Insects 28: 1-12.

Salles, F. F. \& C. M. Polegatto. 2008. Two new species of Baetodes Needham \& Murphy (Ephemeroptera: Baetidae) from Brazil. Zootaxa 1851: 4350 .

Salles, F. F. \& C. Nieto. 2008. Los estados adultos de Nanomis y Spiritiops (Ephemeroptera: Baetidae). Revista de la Sociedad Entomológica Argentina 67: 35-39.

Salles, F. F. \& C. R. Lugo-Ortiz. 2002a. A distinctive new species of Apobaetis (Ephemeroptera: Baetidae) from Mato Grosso and Minas Gerais, Brazil. Zootaxa 35: 1-6.

Salles, F. F. \& C. R. Lugo-Ortiz. 2002b. Primeiro registro do gênero Harpagobaetis Mol (Ephemeroptera: Baetidae) para o Brasil. Lundiana 3: 155.

Salles, F. F. \& J. E. Serrão. 2005. The nymphs of the genus Camelobaetidius Demoulin (Ephemeroptera: Baetidae) in Brazil: new species, new records, and key for the identification of the species. Annales de Limnologie 41: 267-279

Salles, F. F. \& J. M. Cavalcante do Nascimento. 2009. The genus Rivudiva Lugo-Ortiz and McCafferty (Ephemeroptera: Baetidae): First generic description of adults, new combinations, and notes on the nymphs. Annales de Limnologie 45: 231-235.

Salles, F. F. \& L. G. Dias. 2004. Descrição dos adultos de Camelobaetidius billi (Ephemeroptera, Baetidae). Iheringia 94: 209-210.

Salles, F. F.; J. D. Batista \& H. R. S. Cabette. 2004a. Baetidae (Insecta: Ephemeroptera) de Nova Xavantina, Mato Grosso, Brasil: Novos registros e descrição de uma nova espécie de Cloeodes Traver. Biota Neotropica 4: 1-8.

Salles, F. F.; E. R. Da-Silva; M. D. Hubbard \& J. E. Serrão. 2004b. As espécies de Ephemeroptera (Insecta) registradas para o Brasil. Biota Neotropica 4: 1-34.

Salles, F. F.; J. M. Cavalcante do Nascimento; F. C. Massariol; K. B. Angeli; J. A. Rudio; P. Barcelos e Silva \& R. Boldrini. 2010a. Primeiro levantamento da fauna de Ephemeroptera (Insecta) do Espirito Santo. Biota Neotropica 10: 293-307.

Salles, F. F.; E. A. Raimundi; R. Boldrini \& G. M. Souza-Franco. 2010b. The genus Americabaetis Kluge (Ephemeroptera: Baetidae) in Brazil: new species, stage description, and key to nymphs. Zootaxa 2560: 16-28.

Salles, F. F.; R. Boldrini; J. M. Cavalcante do Nascimento; Y. F. Shimano \& E. Raimundi. 2011a. Check list das espécies de Ephemeroptera registradas para o Brasil. Disponível em http://ephemeroptera.br.googlepages.com/ home (acessado 10 de fevereiro de 2011).

Salles, F. F; R. Boldrini; Y. F. Shimano \& H. R. S. Cabette. 2011b. Review of the genus Aturbina Lugo-Ortiz \& McCafferty (Ephemeroptera: Baetidae). Annales de Limnologie 47: 21-44.

Souza, M. R.; F. F. Salles \& J. L. Nessimian. No prelo. Three new species of Baetodes Needham \& Murphy (Ephemeroptera: Baetidae) from the Espírito Santo State. Aquatic Insects.

Thomas, A.; Y. Dominique \& V. Horeau. 2003. Les Ephémères de la Guyane Française. 7. Redescription de Camelobaetidius cayumba (Traver \& Edmunds, 1968) [Ephemeroptera: Baetidae]. Ephemera 2001 3: 117-122.

Thomas, A. \& N. Peru. 2003. Les Éphémères de la Guyane Française 6. Description de Waltzoyphius roberti n. sp. [Ephemeroptera, Baetidae]. Bulletin de la Société d'Histoire Naturelle de Toulouse (2002) 138 : 15-20.

Traver, J. R. \& G. F. Edmunds Jr. 1968. A revision of the Baetidae with spatulate-clawed nymphs (Ephemeroptera). Pacific Insects 10: 629-677. 